\title{
A Convergent and Stereoselective Method for the Synthesis of Acyclic $\alpha$-Chloroenamides
}

\author{
Richard R. Surgenor, Andrea C. Grote, Catherine McGeough, Arjun Narayanan, Wenyu Wang* \\ and Philip N. Collier* \\ Corresponding authors: wenyu_wang@vrtx.com, philip collier@vrtx.com \\ Vertex Pharmaceuticals Incorporated, 50 Northern Avenue, Boston, Massachusetts, 02210, United \\ States of America
}

\section{Supporting Information}




\section{Table of Contents}

1. Base screen for amidinium ion hydrolysis conditions S3

2. 2D NMR spectra

3. ${ }^{1} \mathrm{H}$ and ${ }^{13} \mathrm{C}$ NMR spectra

S9 


\section{Base screen for amidinium ion hydrolysis conditions}<smiles>[R]C([R])=C(Cl)N([R])C=[N+](C)C</smiles>

S4

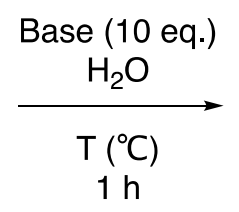

$\mathrm{h}$<smiles>[R]C([R])=C(Cl)N([R])CO</smiles>

S5a<smiles>[R]C([18F])C(=O)N([R])CO</smiles>

S5b<smiles>[R]NC(=O)C([R])[R]</smiles>

S5c

A small sample vial was charged with the chloride salt of $\mathbf{S 4}(0.60 \mathrm{mmol})$ and was treated with an aqueous solution ( $1 \mathrm{~mL}, 10.0$ eq., $6 \mathrm{M}$ ) of the chosen base. The mixture was then vigorously stirred at the specified temperature for the specified time. The composition of the reaction mixtures was then analyzed by LCMS of the crude reactions. The relative peak areas (\%) of the major components of the reaction are reported below.

$\begin{array}{llllllll}\text { Entry } & \text { Base } & \text { Time (min) } & \text { Temp. }\left({ }^{\circ} \mathrm{C}\right) & S 4(\%) & S 5 a(\%) & S 5 b(\%) & S 5 c(\%) \\ 1 & \mathrm{Na}_{2} \mathrm{CO}_{3} & 60 & r t & <1 & 61 & 25 & 8 \\ 2 & \mathrm{~K}_{2} \mathrm{CO}_{3} & 60 & r t & <1 & 94 & <1 & <1 \\ 3 & \mathrm{Cs}_{2} \mathrm{CO}_{3} & 60 & r t & <1 & 79 & 7 & 9 \\ 4 & \mathrm{LiOH} & 60 & r t & 8 & 80 & 1 & 7 \\ 5 & \mathrm{NaOH} & 60 & r t & <1 & 84 & 6 & 6 \\ 6 & \mathrm{KOH} & 60 & r t & <1 & 57 & 27 & 8 \\ 7 & \mathrm{nobase} & 60 & 60 & 37 & <1 & 31 & 30 \\ 8 & \mathrm{nobase} & 10 & 90 & 53 & 2 & 25 & 21 \\ 9 & \mathrm{Cs} \mathrm{CO}_{3} & 60 & 60 & <1 & 26 & 26 & 39 \\ 10 & \mathrm{LiOH} & 60 & 60 & 1 & 82 & 3 & 6 \\ 11 & \mathrm{NaOH} & 60 & 60 & 5 & 51 & 27 & 15 \\ 12 & \mathrm{KOH} & 60 & 60 & 6 & 42 & 30 & 15\end{array}$

\section{Conclusion}

No improved conditions were found than those originally reported by Sarpong (ie. Entry 2). No further optimization was carried out. 


\section{2D NMR spectra}

\section{NOESY Spectra and Determination of Alkene Geometry}

The geometry of the trisubstituted $\alpha$-chloroenamide products were determined by NOESY NMR experiments, as exemplified below by product 15a (isolated in 19:1 mixture of isomers). The major isomer showed an nOe correlation between formyl $\mathrm{H}_{\mathrm{a}}$ and $\mathrm{H}_{\mathrm{B}}$ of alkene (Depicted by black arrow) indicating that the Z-product was the major isomer.
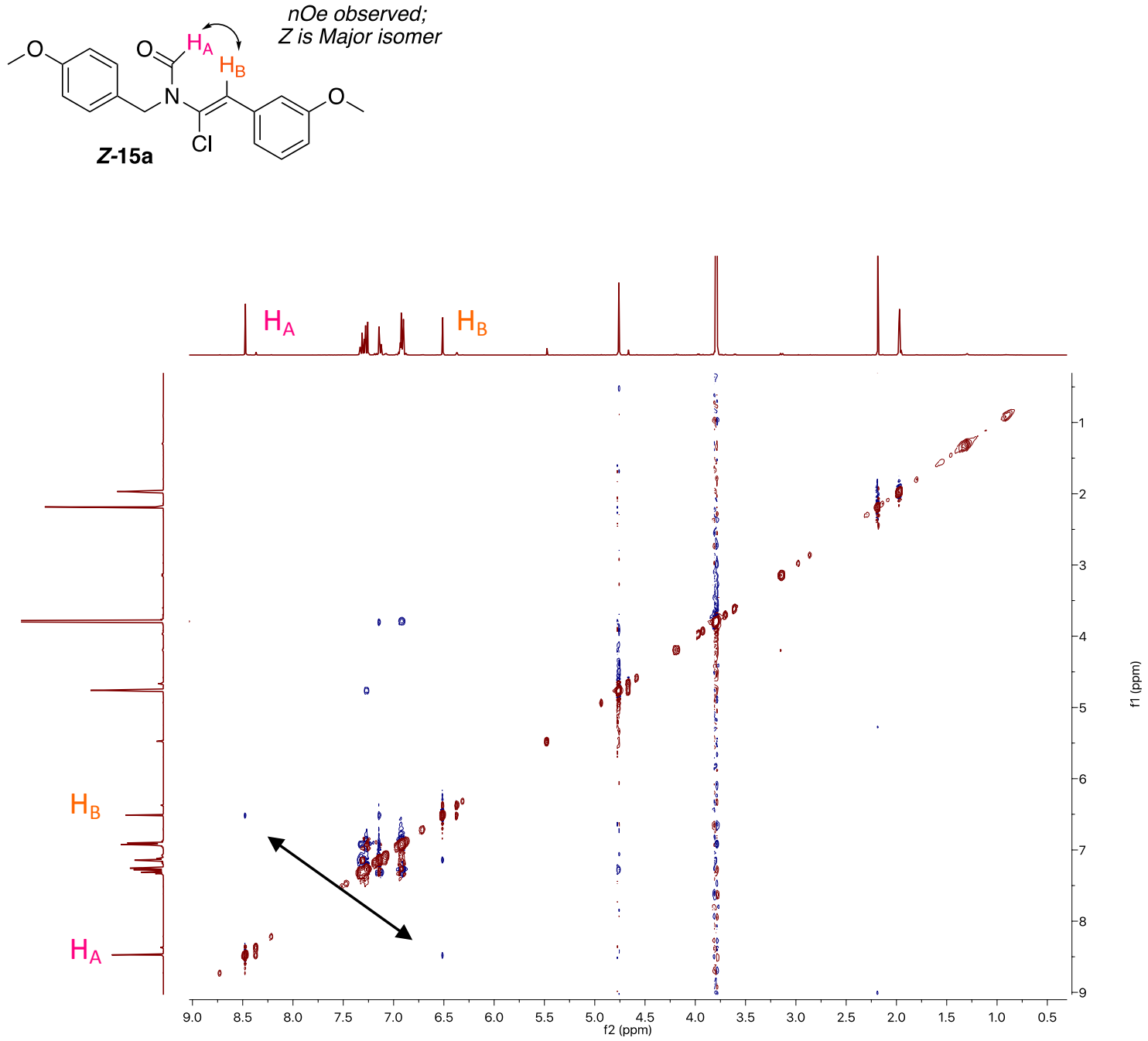
For the tetrasubstituted $\alpha$-chloroenamide products, we expected to observe an nOe correlation between formyl $\mathrm{H}_{\mathrm{a}}$ and the methylene $H_{B}$ adjacent to the double bond for the Z-isomer and not to observe this correlation for the Eisomer.

In a control experiment, amidinium $\mathbf{S 6}$ was synthesized that indeed showed strong nOe correlations between $\mathrm{H}_{\mathrm{a}}$ and both methylene $\mathrm{H}_{\mathrm{B}}$ protons. (Corresponding formyl product could not be isolated due to stability issues)

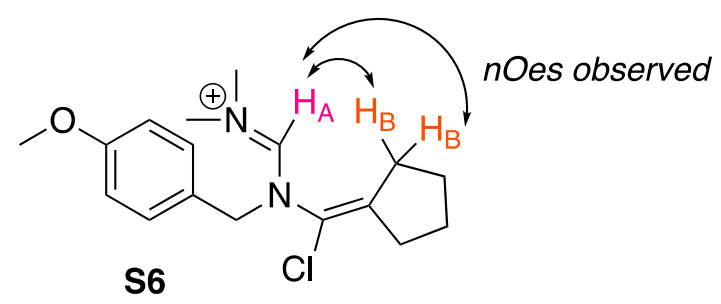

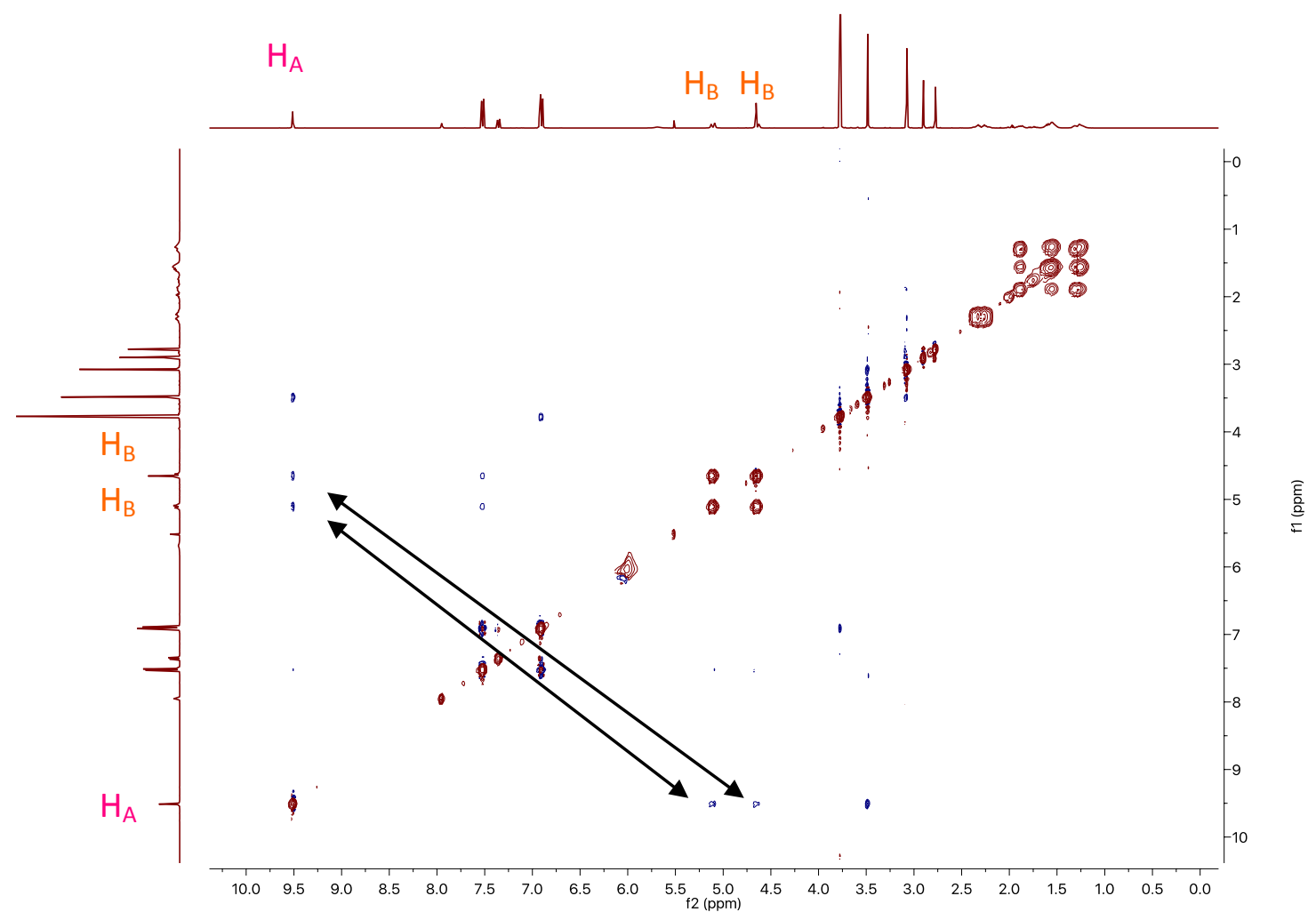


For product 15h (isolated as $>20: 1$ mixture of isomers), no nOes between $\mathrm{H}_{\mathrm{A}}$ and $\mathrm{H}_{\mathrm{B}}$ were observed, therefore the Eproduct was the major isomer.
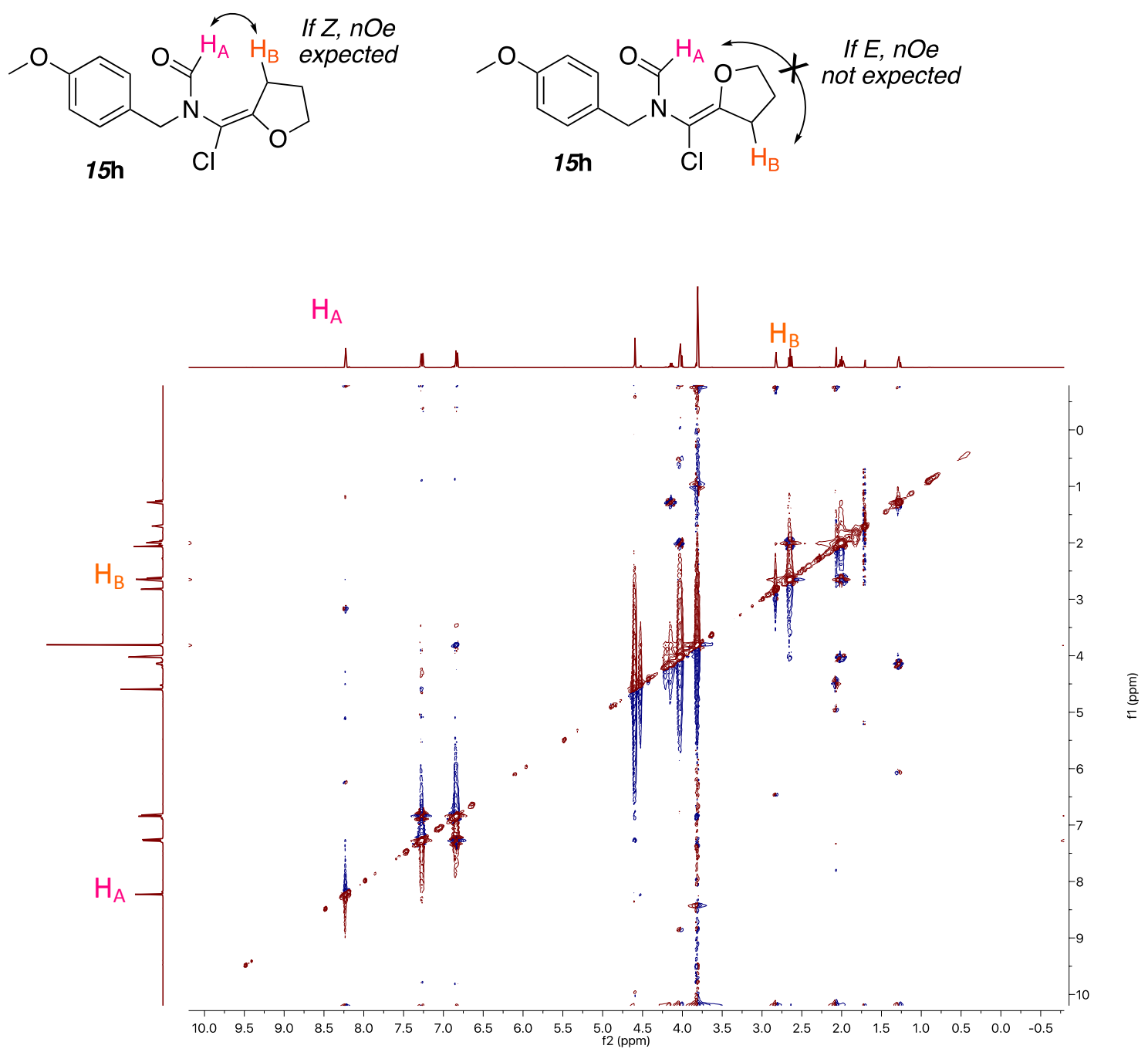
For product 15i (isolated as 7:1 mixture of isomers), no nOes between $\mathrm{H}_{A}$ and $\mathrm{H}_{B}$ were observed, so the E-product was the major isomer.
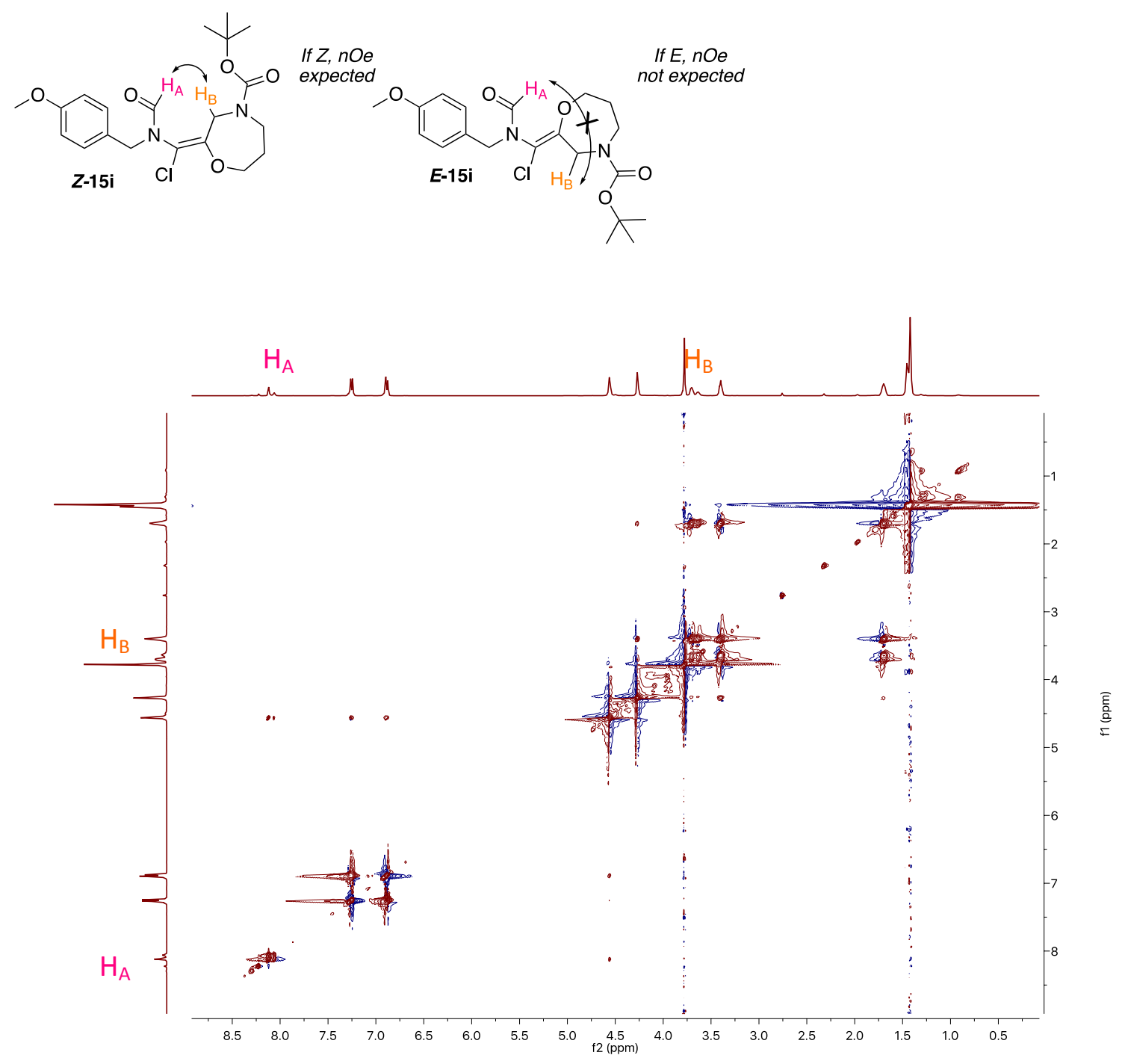
Because nOe signal between $\mathrm{H}_{A}$ and $\mathrm{H}_{B}$ was observed, the major diastereomer of the cycloadduct $\mathbf{2 4}$ should be the endo-diastereomer.

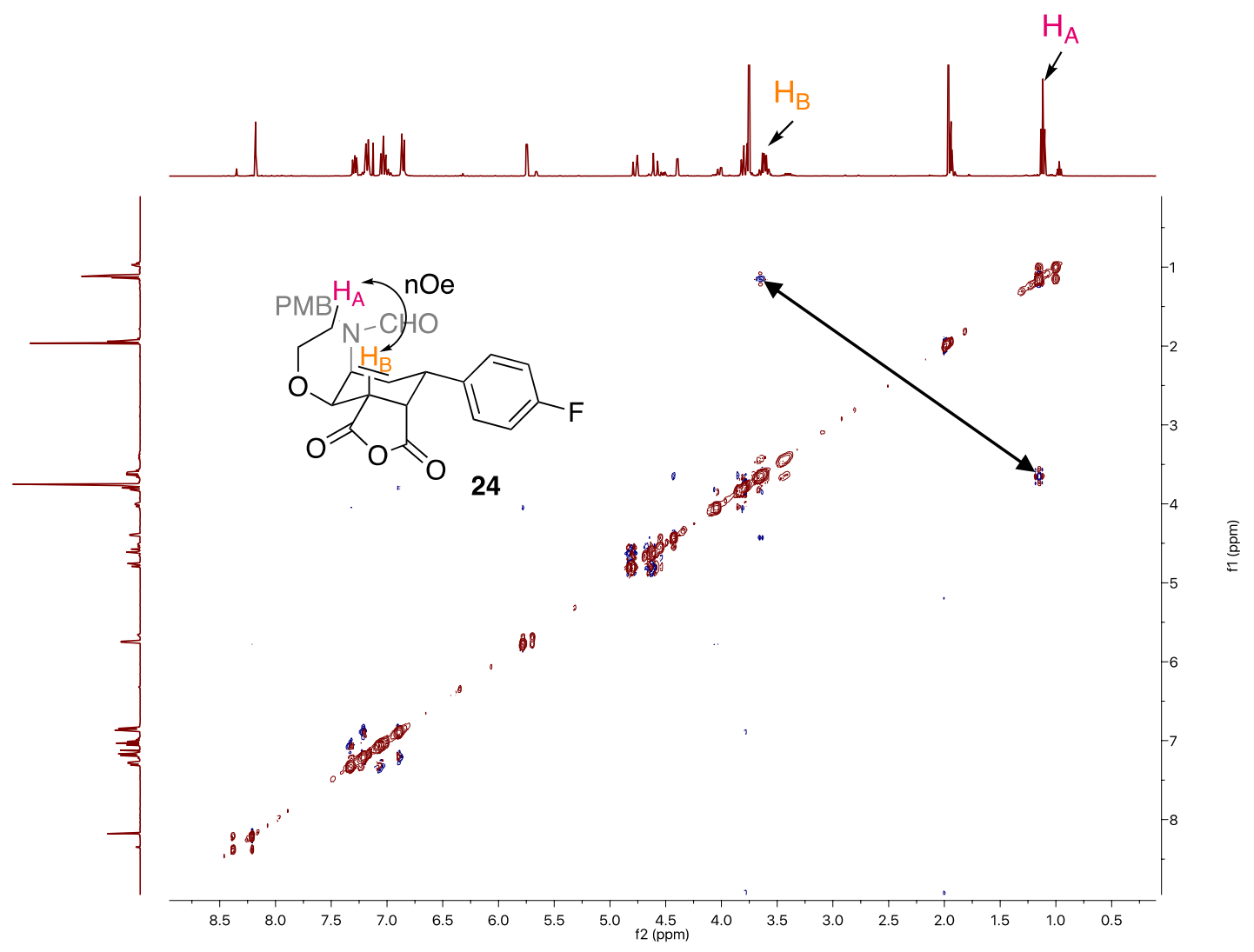




\section{3. ${ }^{1} \mathrm{H}$ and ${ }^{13} \mathrm{C}$ NMR Spectra}
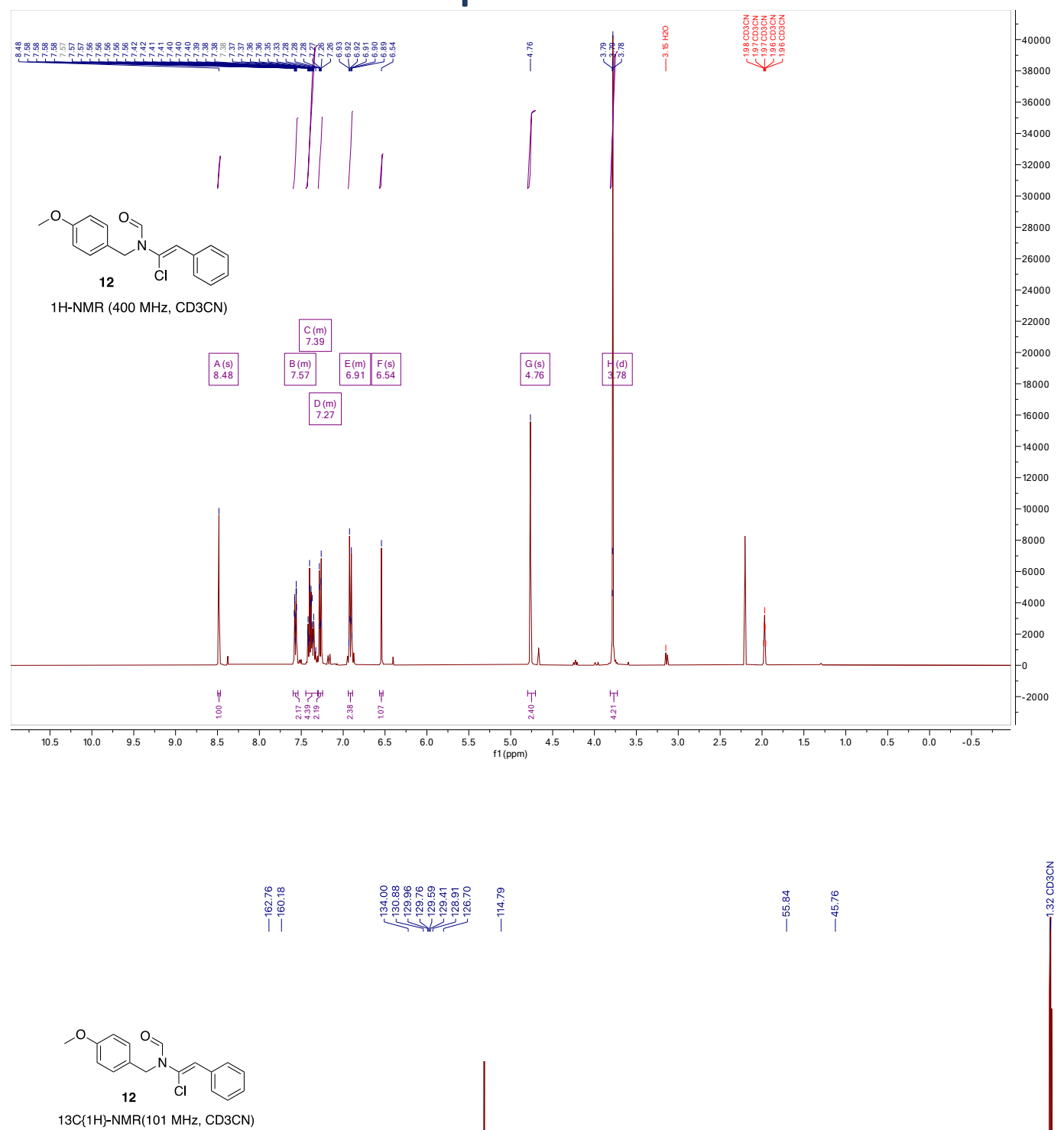

13C $\{1 \mathrm{H}\}-N M R(101 \mathrm{MHz}, \mathrm{CD} 3 \mathrm{CN})$

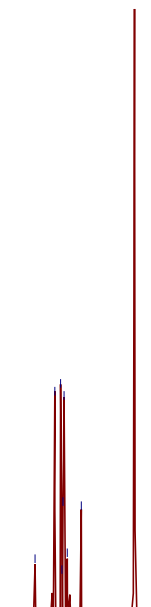

\begin{tabular}{|lllllllllllllllllllllllllllll}
\hline & 210 & 200 & 190 & 180 & 170 & 160 & 150 & 140 & 130 & 120 & 110 & 100 & 10 & 80 & 70 & 60 & 50 & 40 & 30 & 20 & 10 & 0 & -10
\end{tabular} 

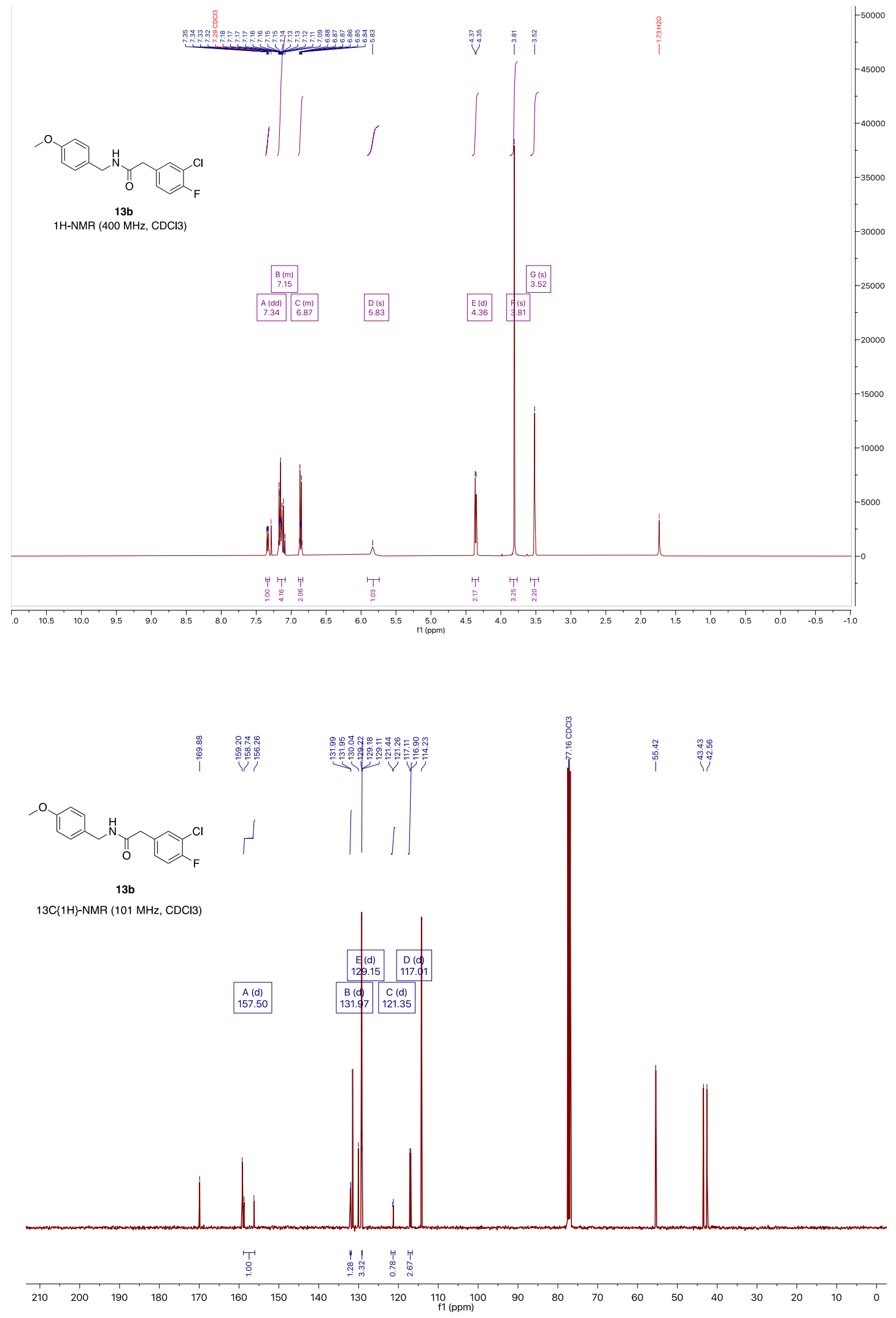


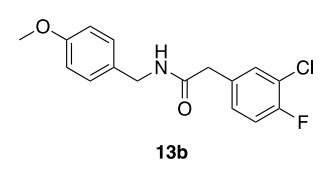

19F-NMR (376 MHz, CDCl3)
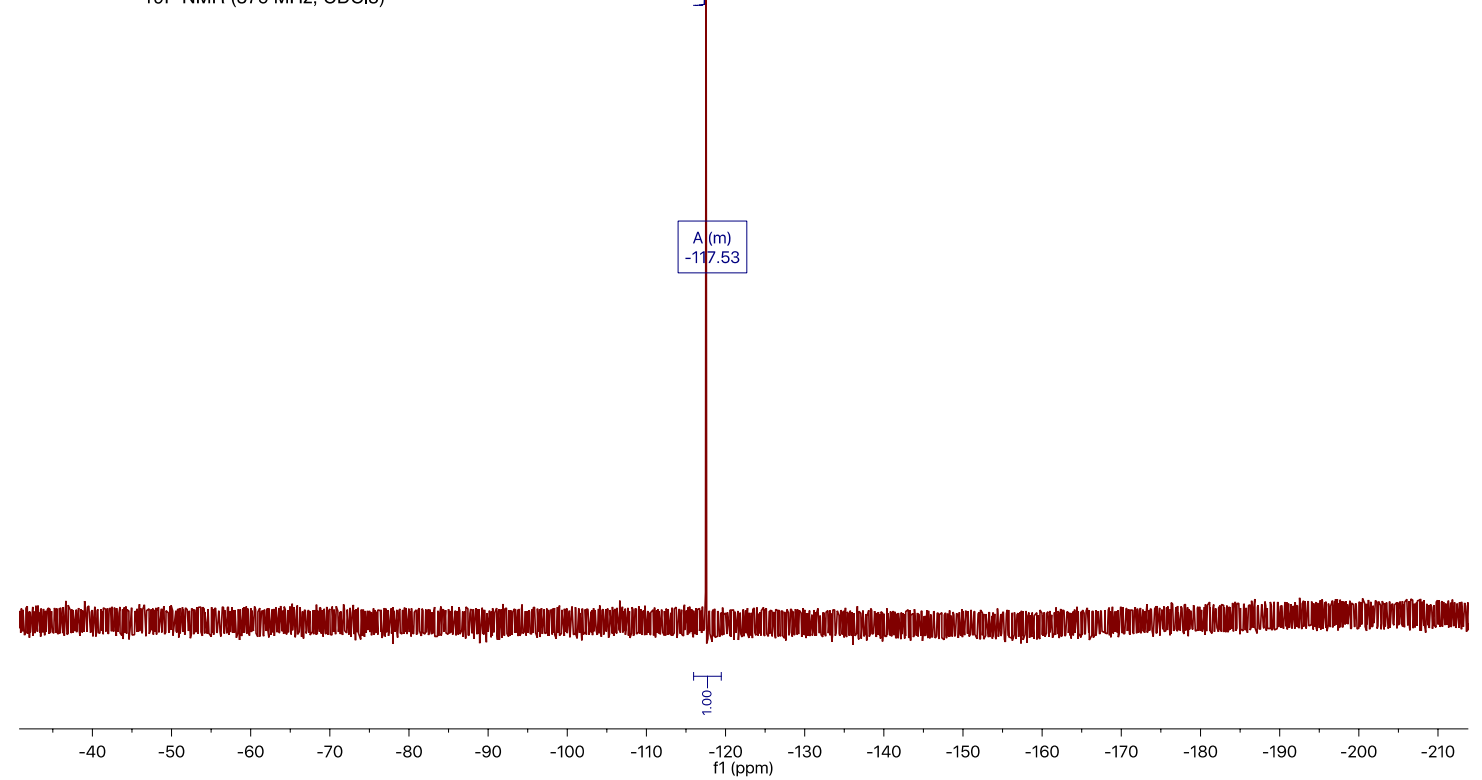

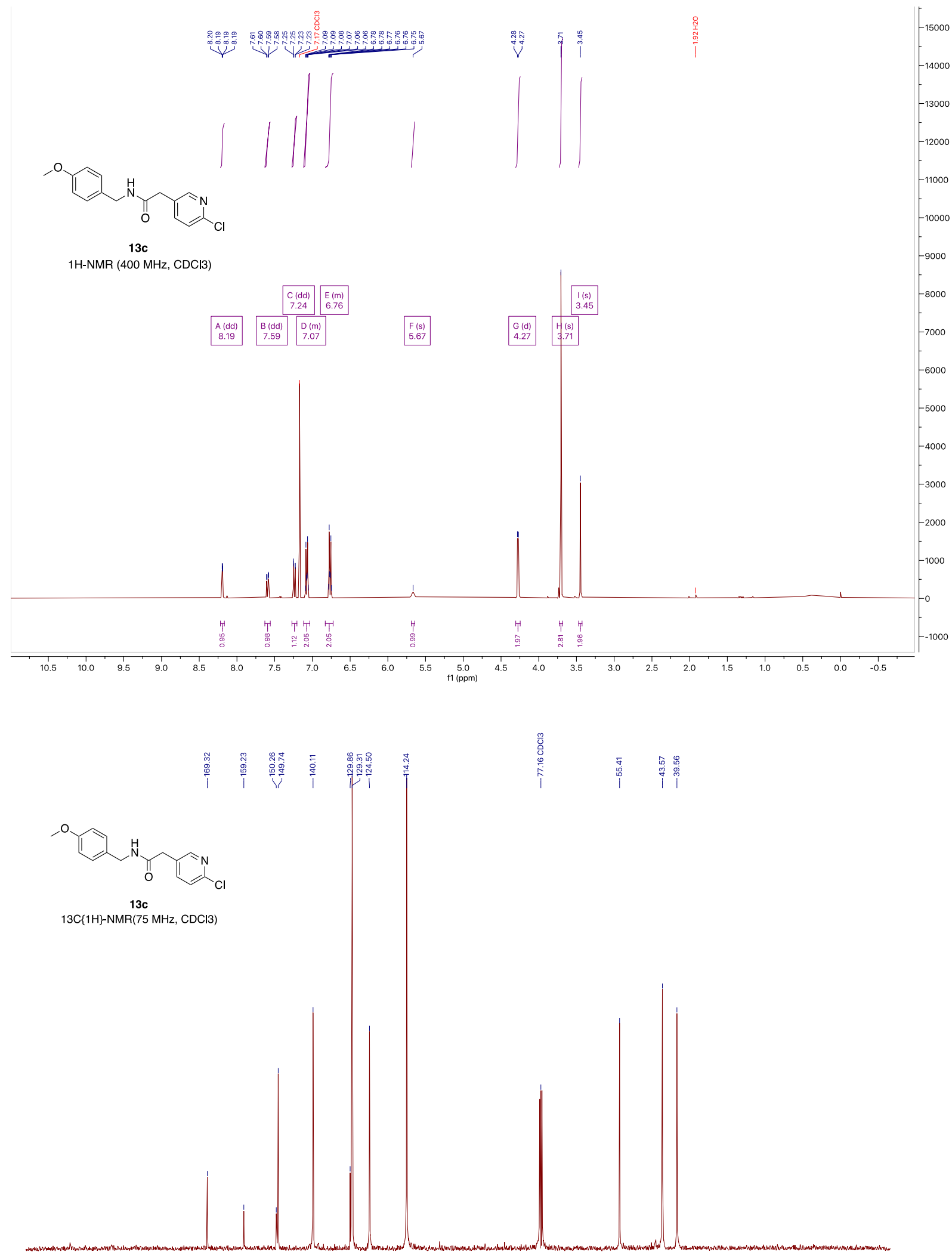

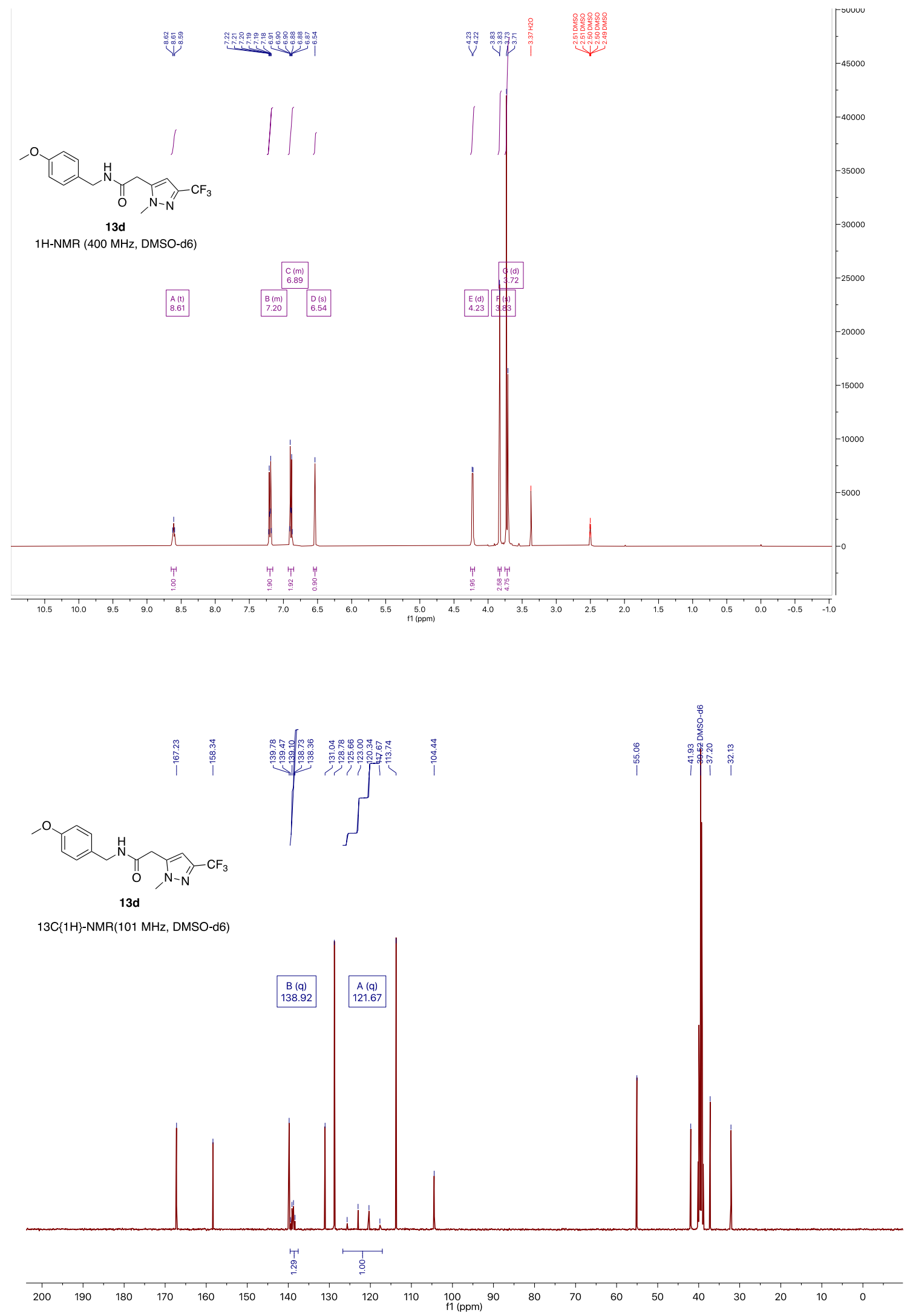


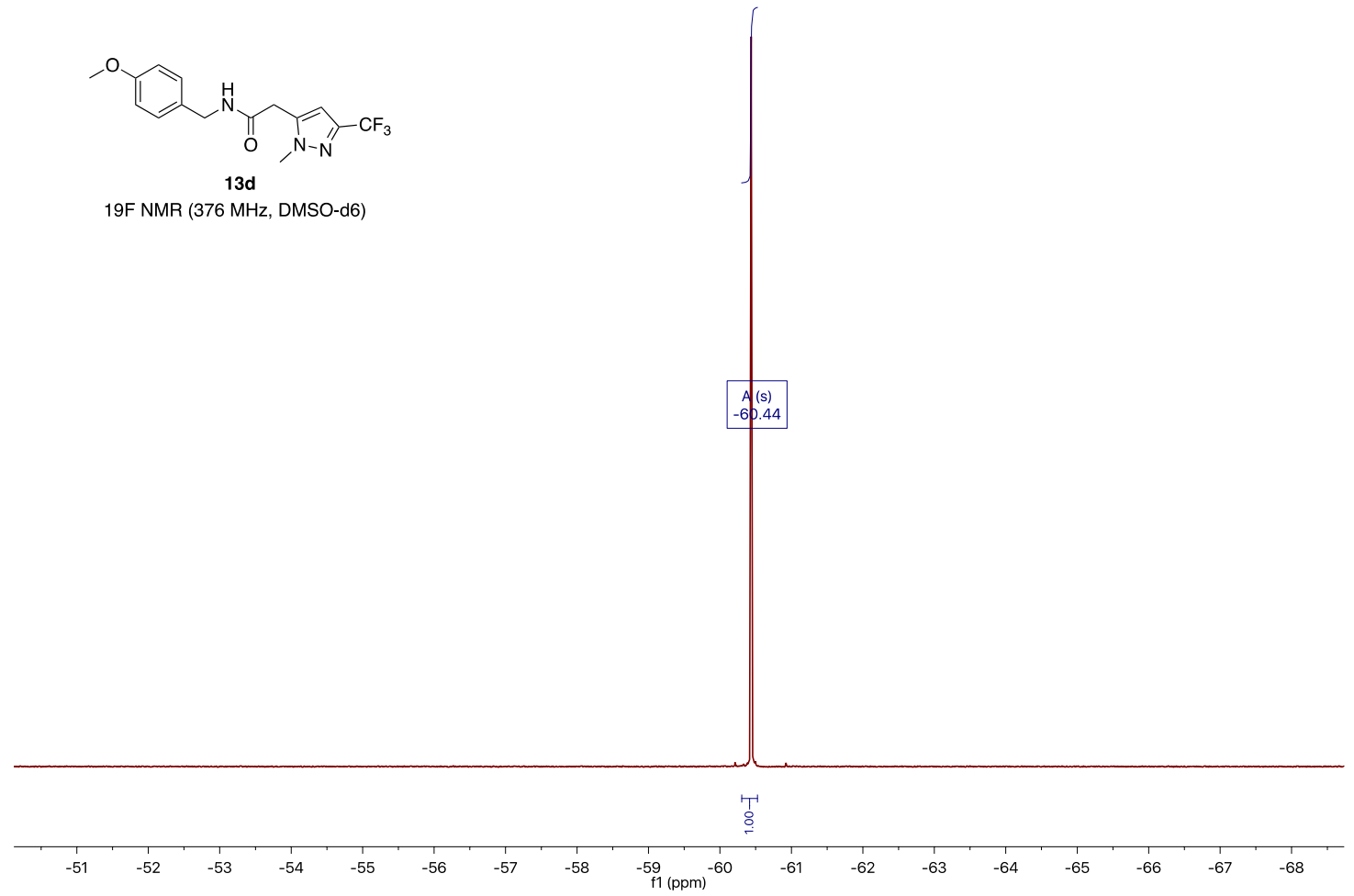



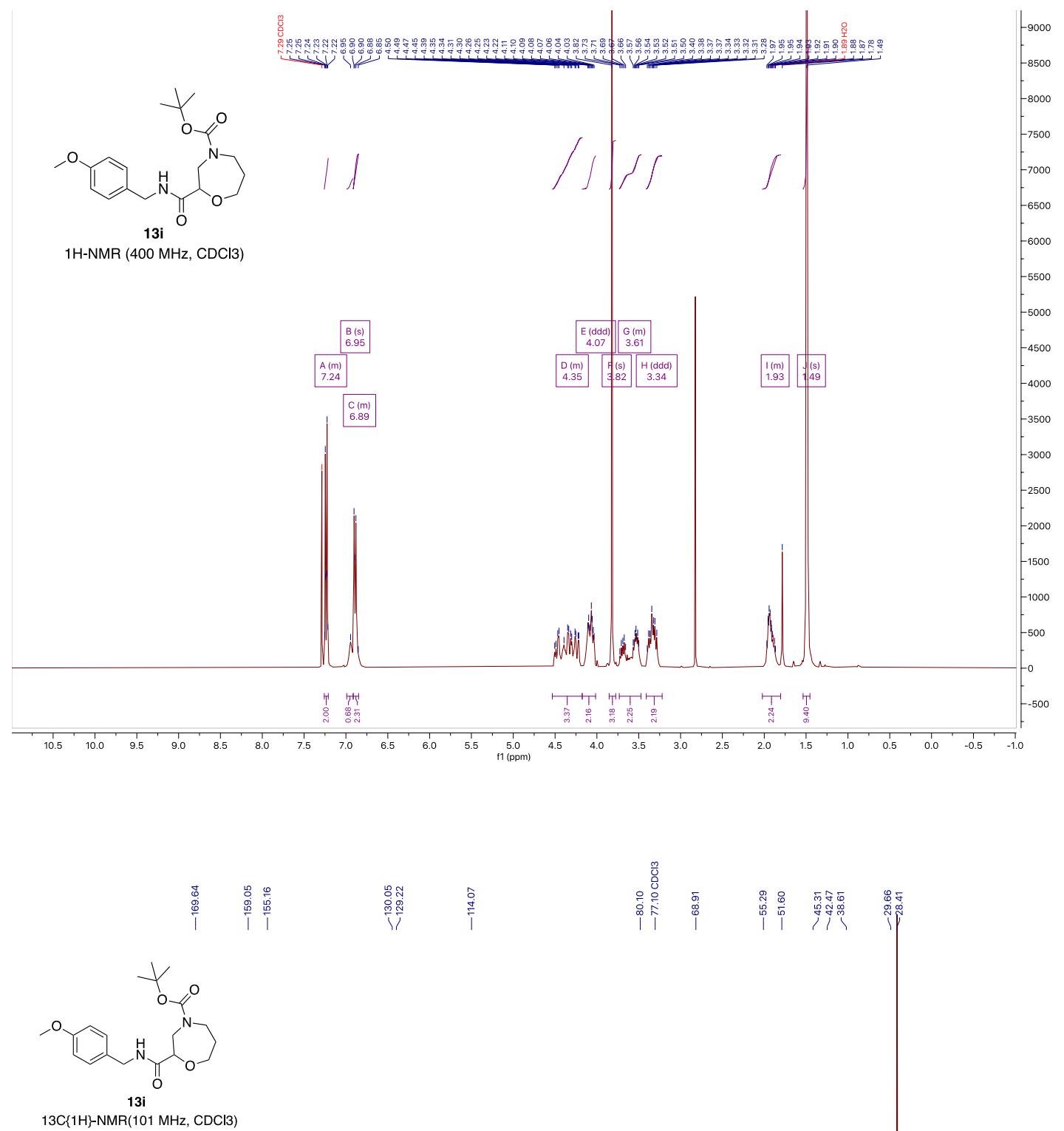

13C\{1H\}-NMR(101 MHz, CDCl3)

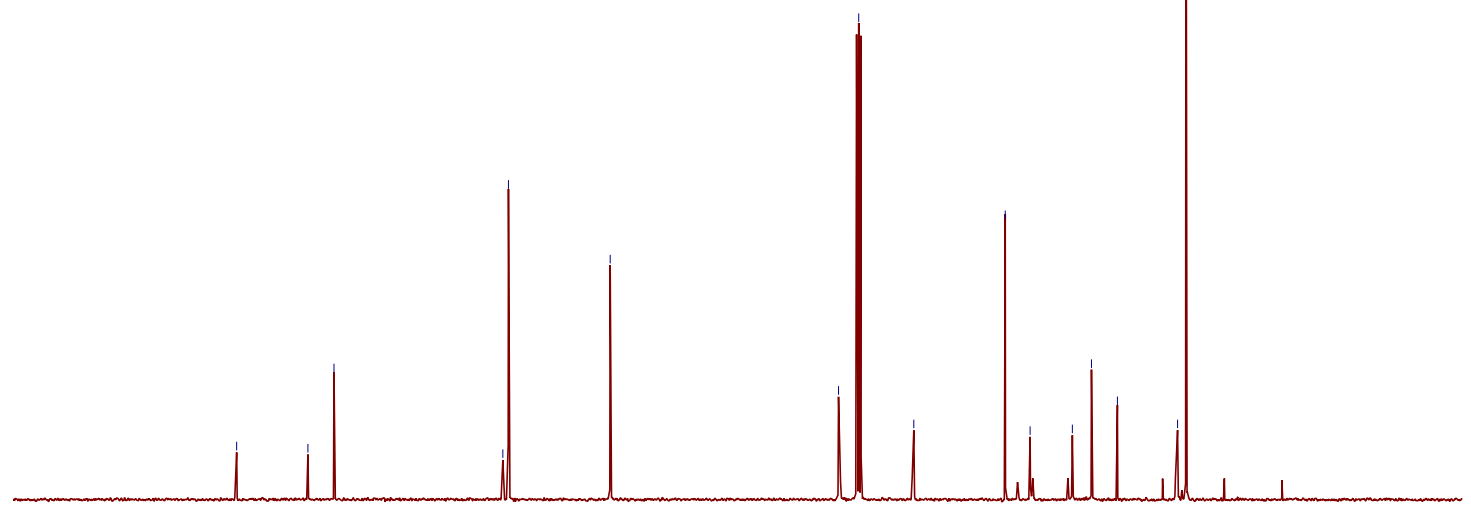

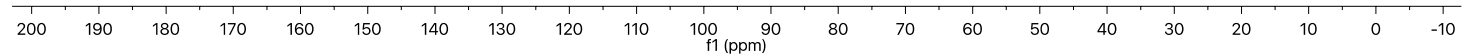



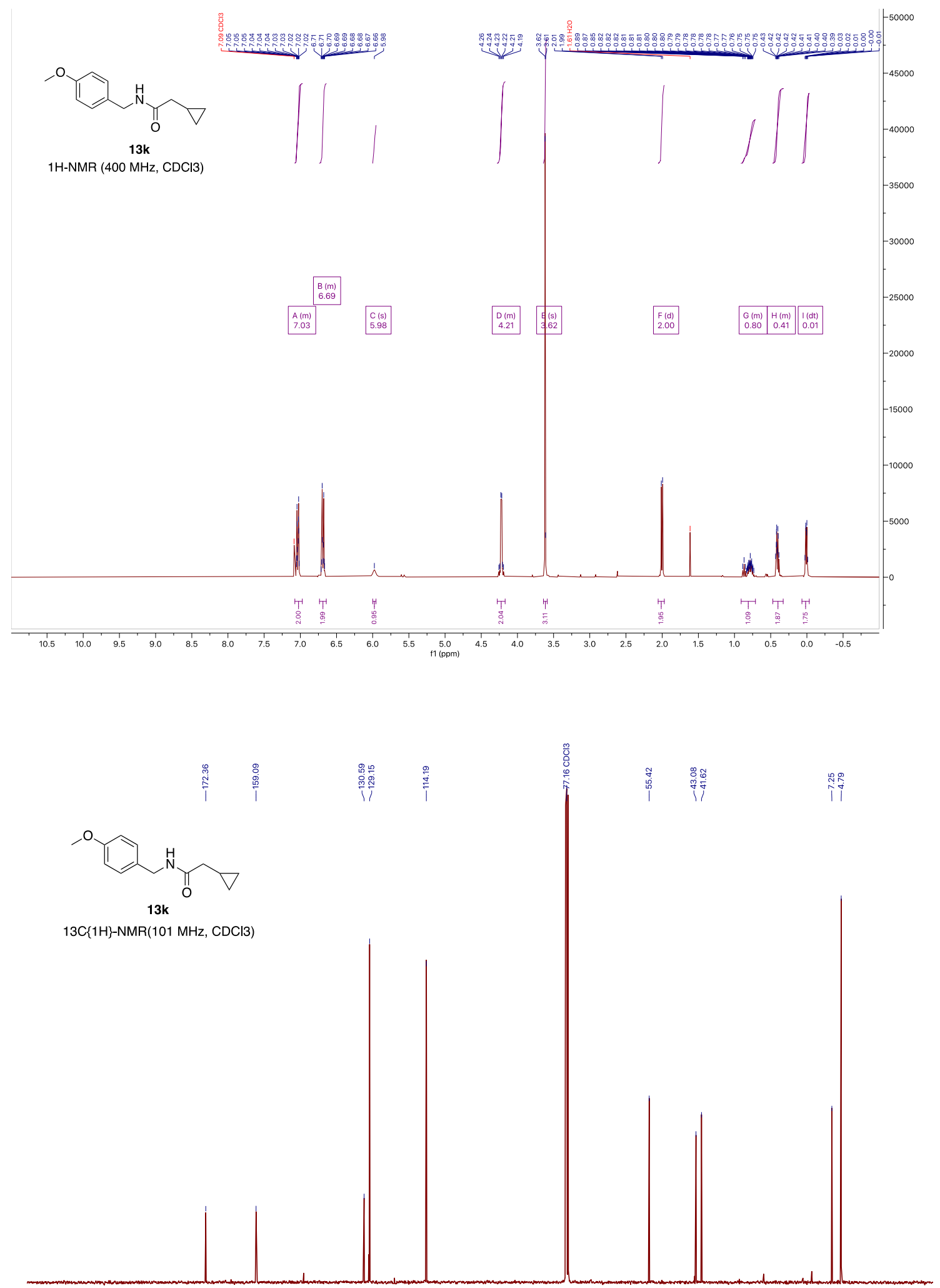

$\begin{array}{llllllllllllllllllllllllll}210 & 200 & 190 & 180 & 170 & 160 & 150 & 140 & 130 & 120 & 110 & 100 & 90 & 80 & 70 & 60 & 50 & 40 & 30 & 20 & 10 & 0 & -10\end{array}$ 

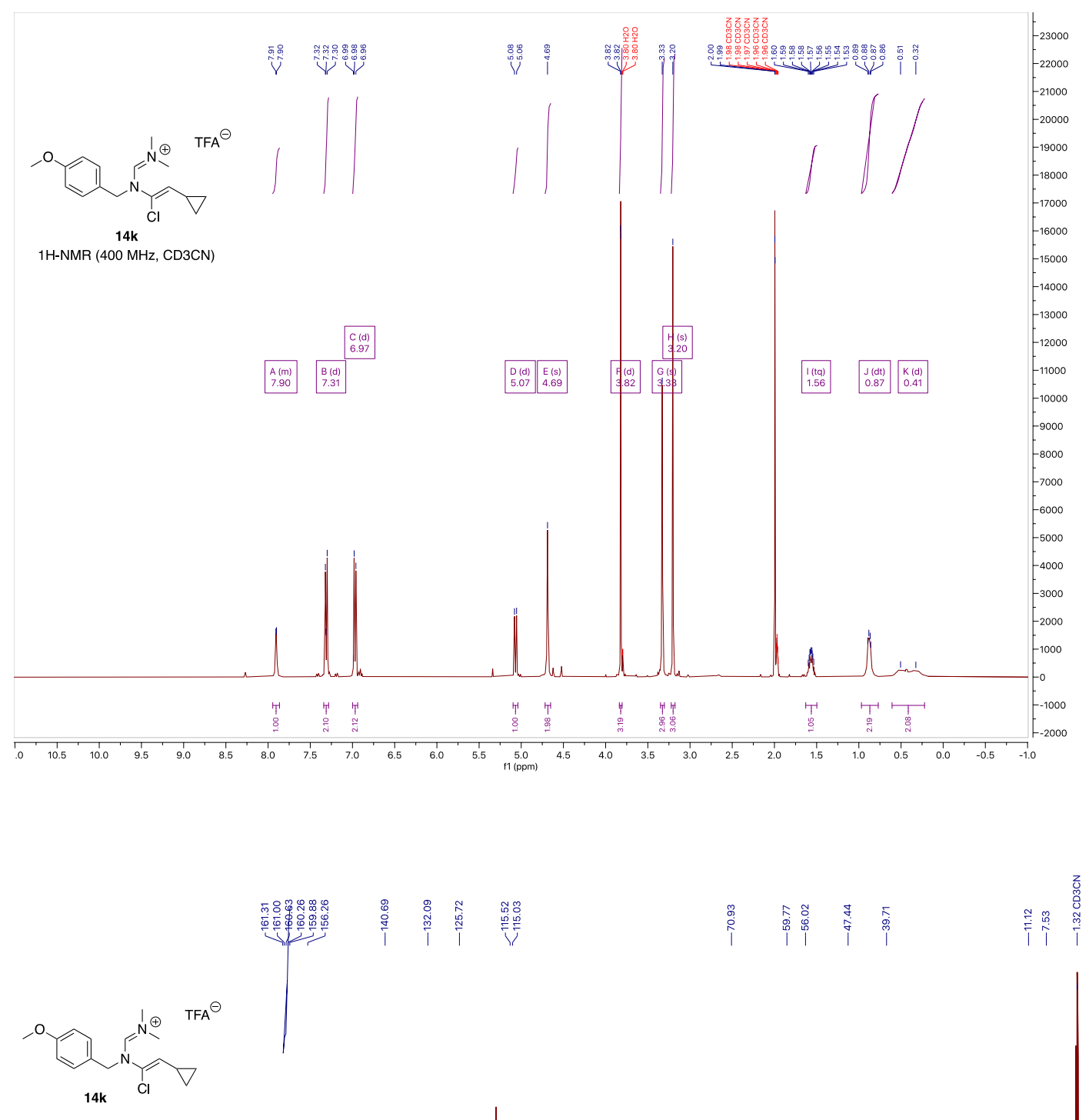

13C\{1H\}-NMR(101 MHz, CD3CN)

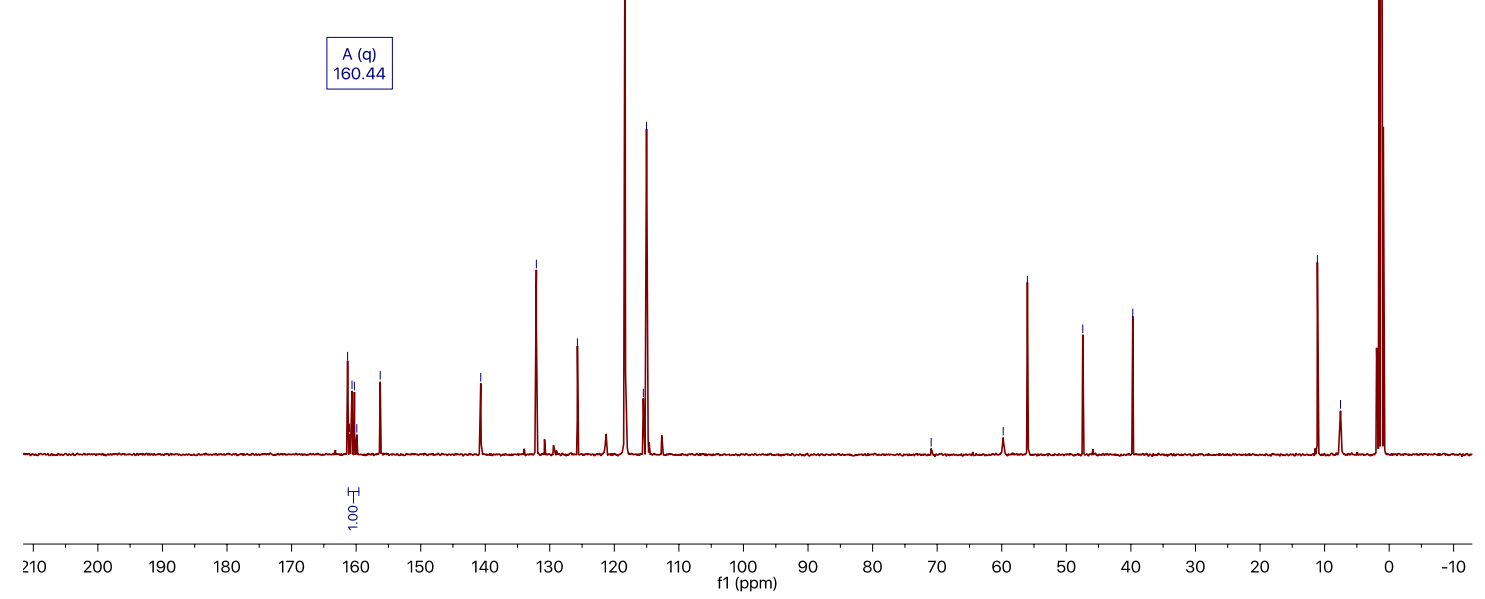




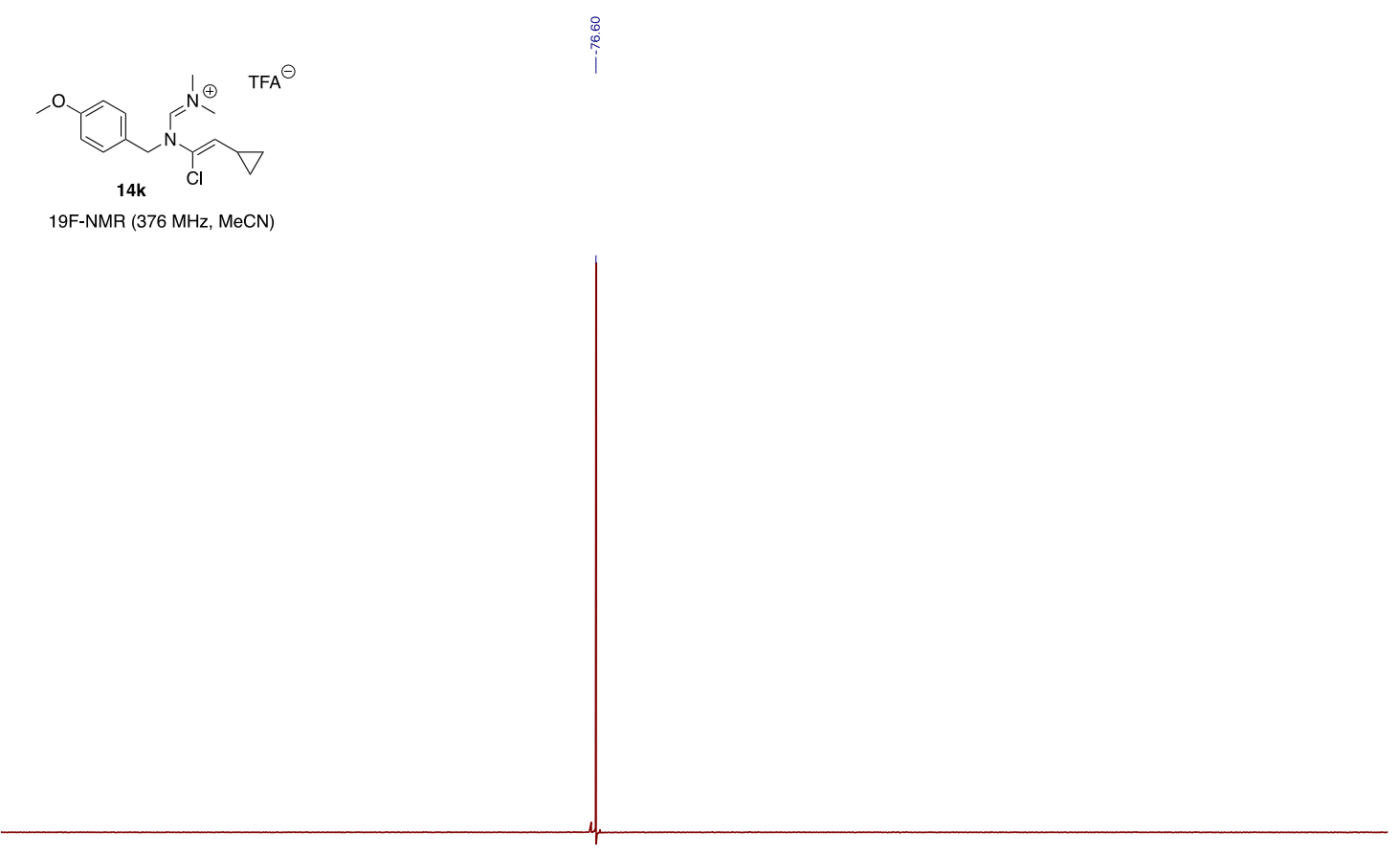

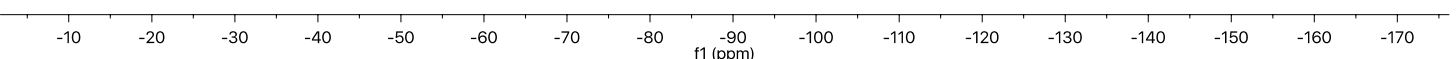



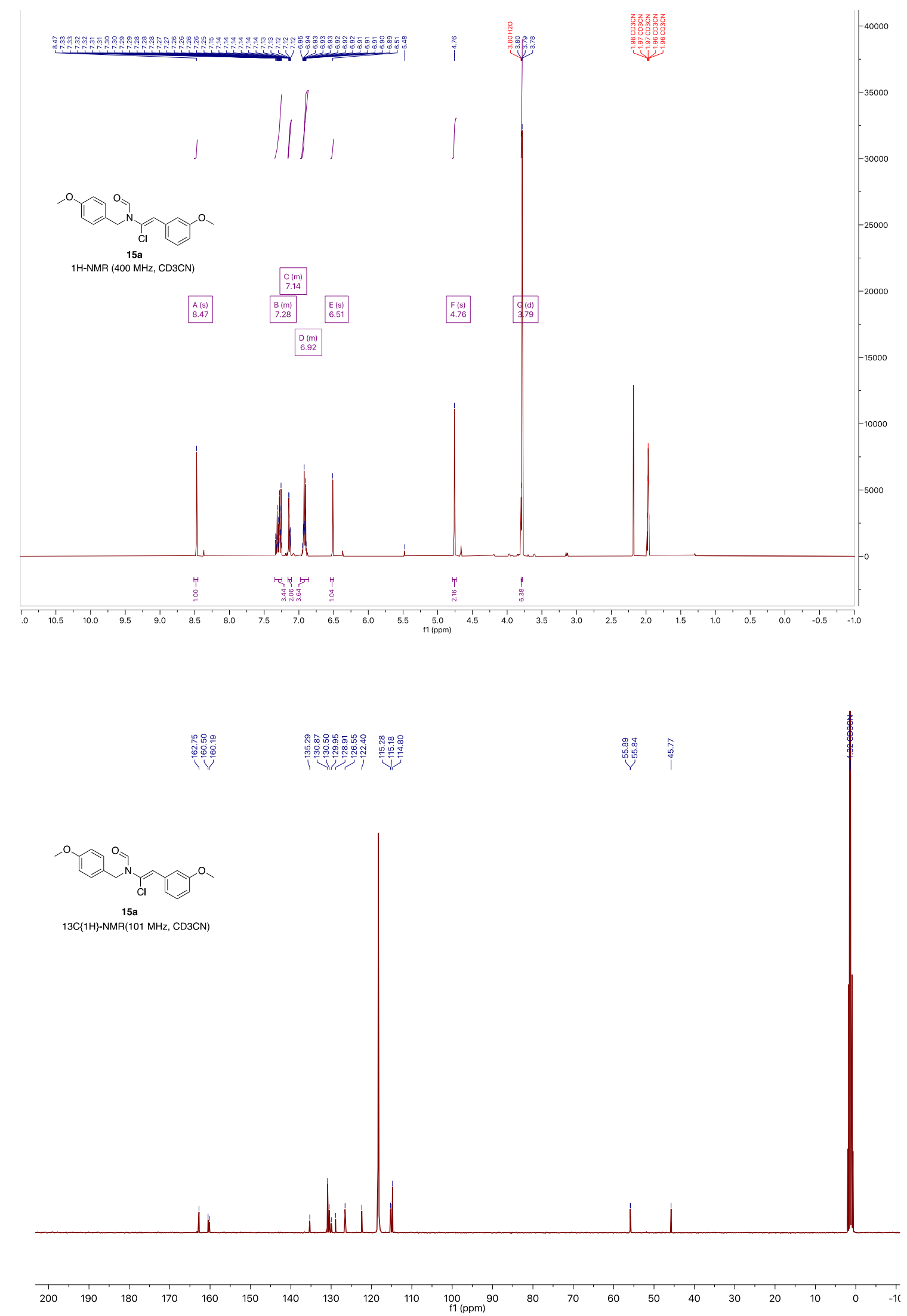


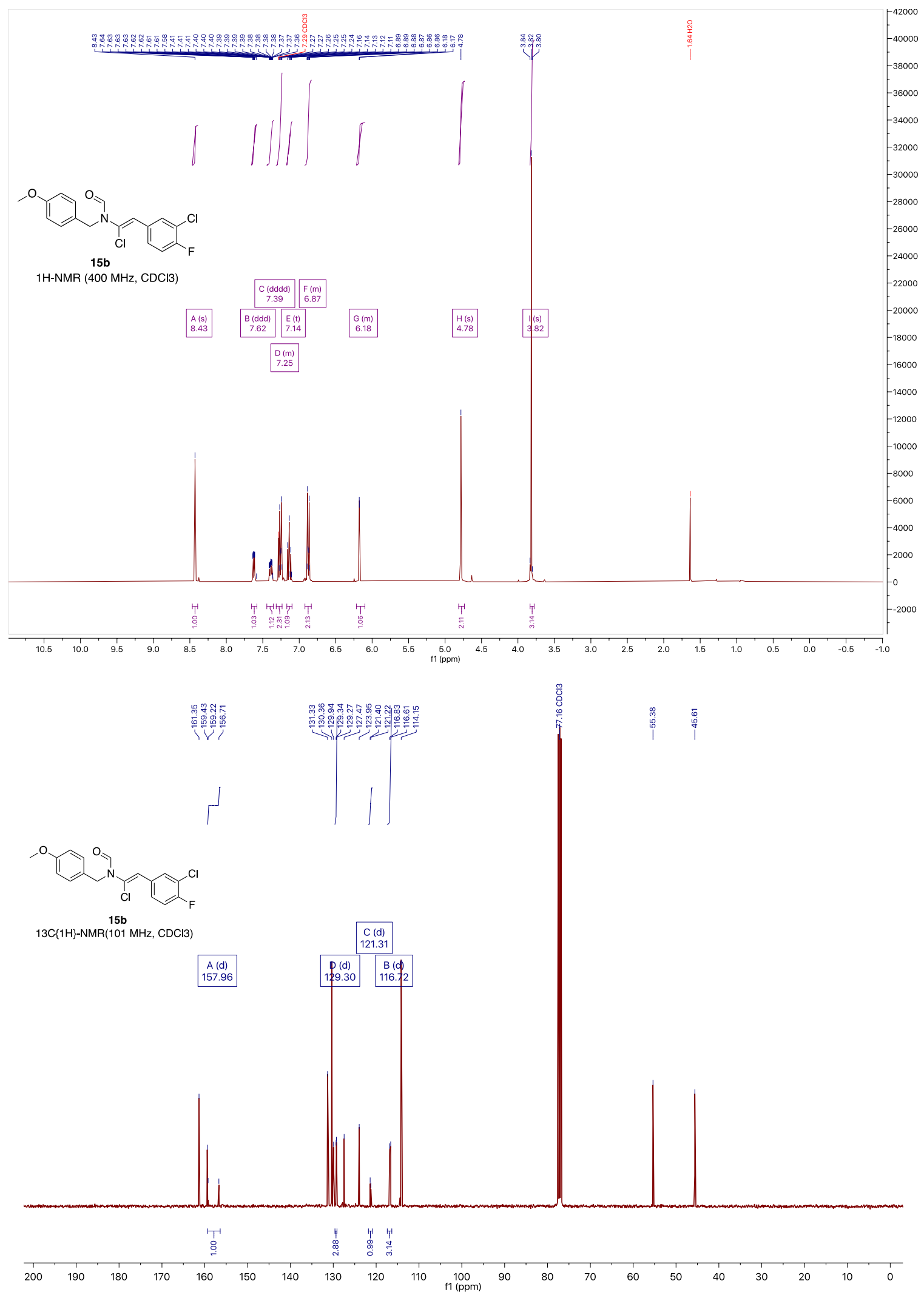



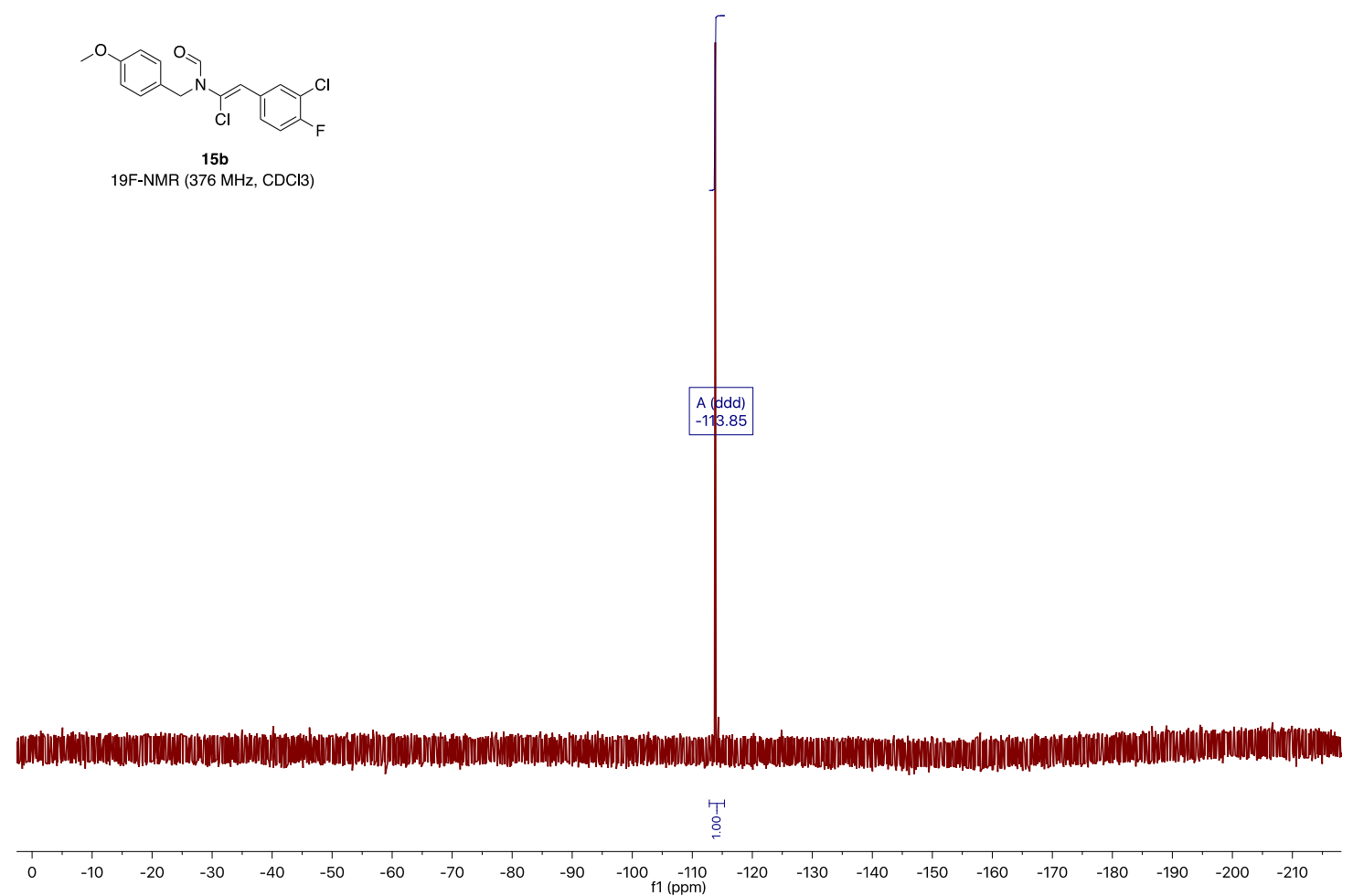

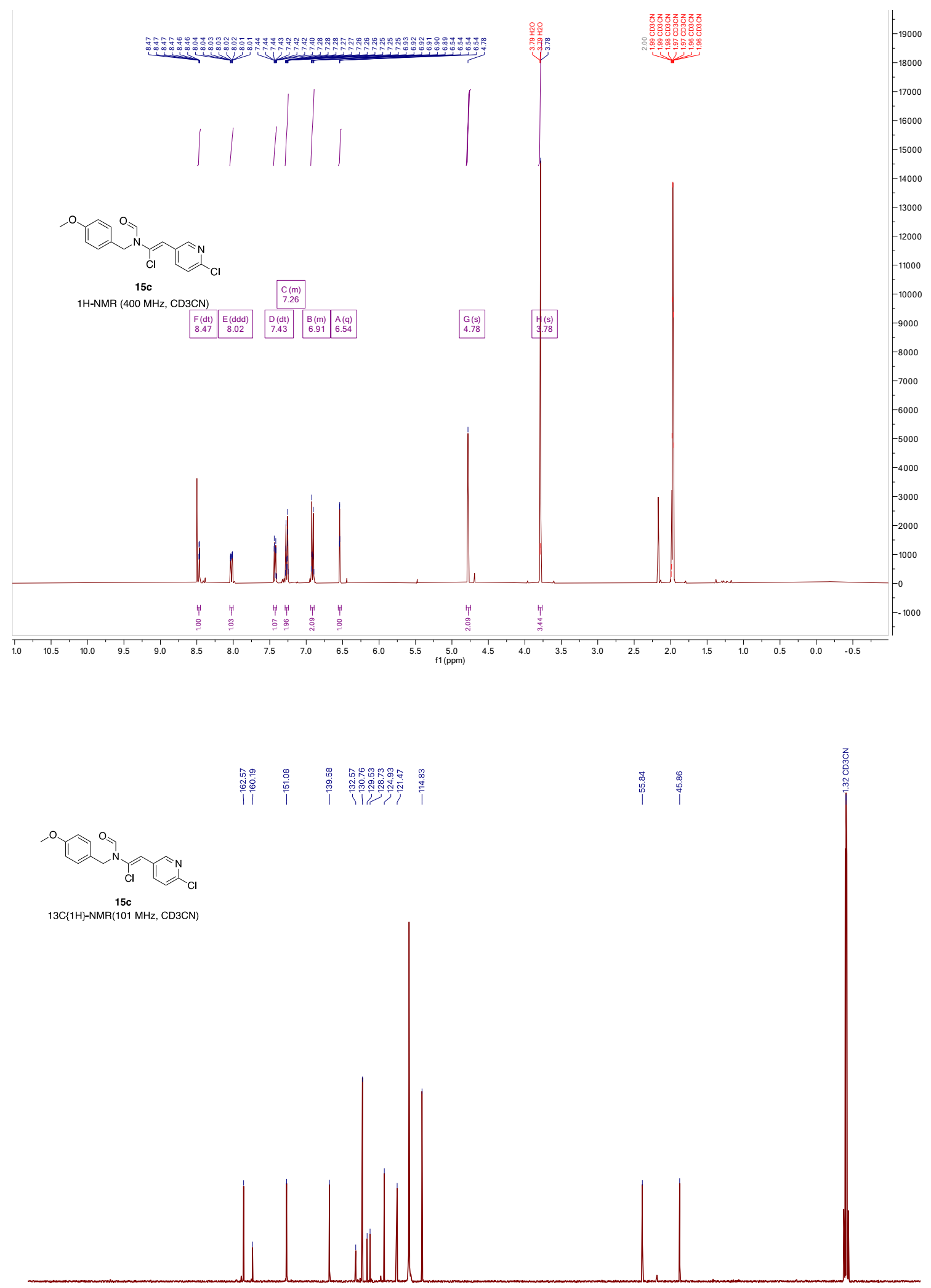

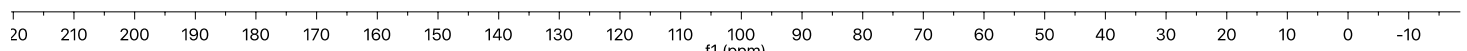



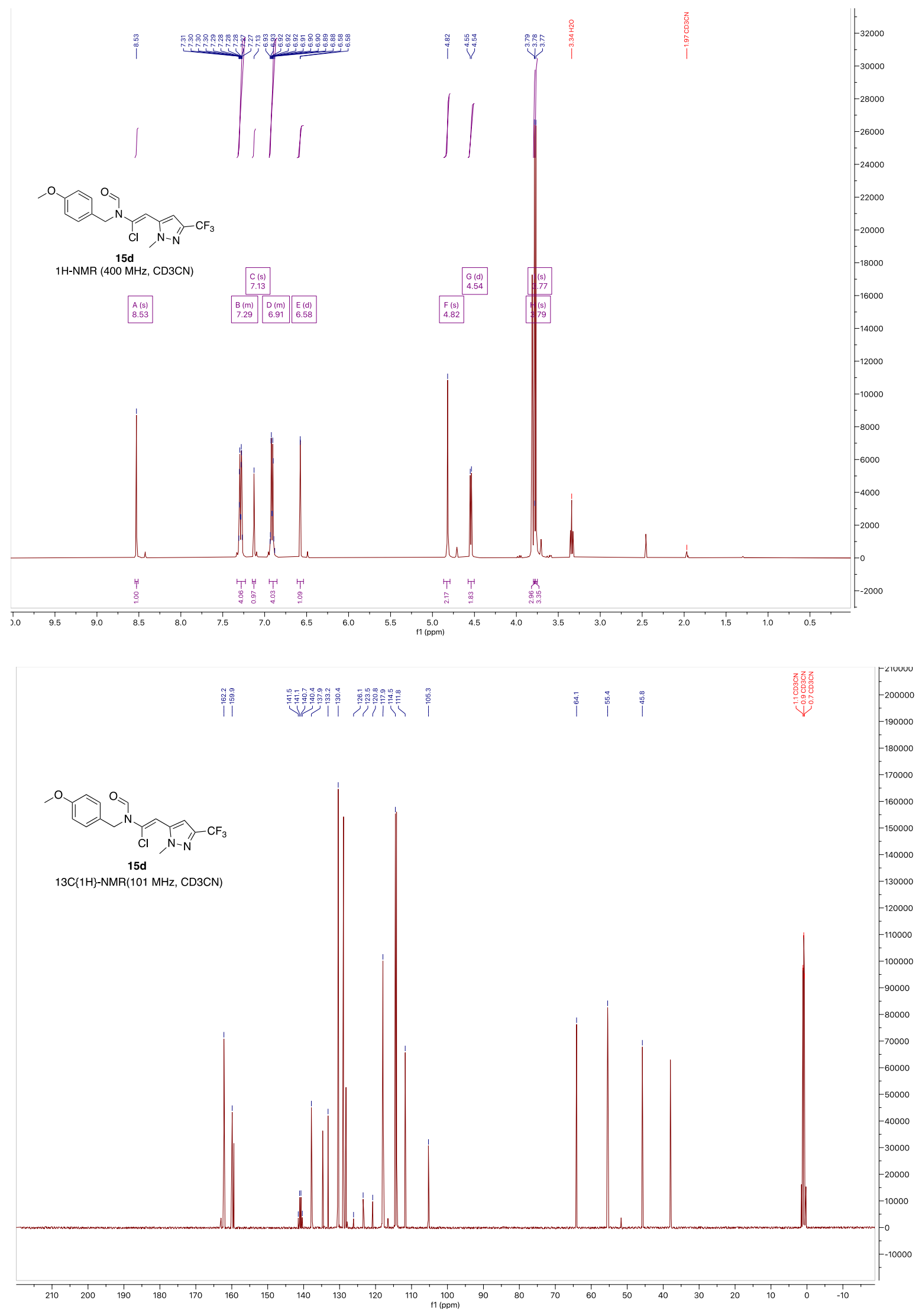


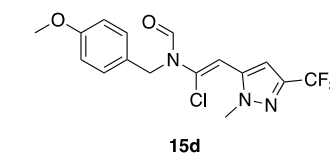

19F-NMR (376 MHz, CD3CN)

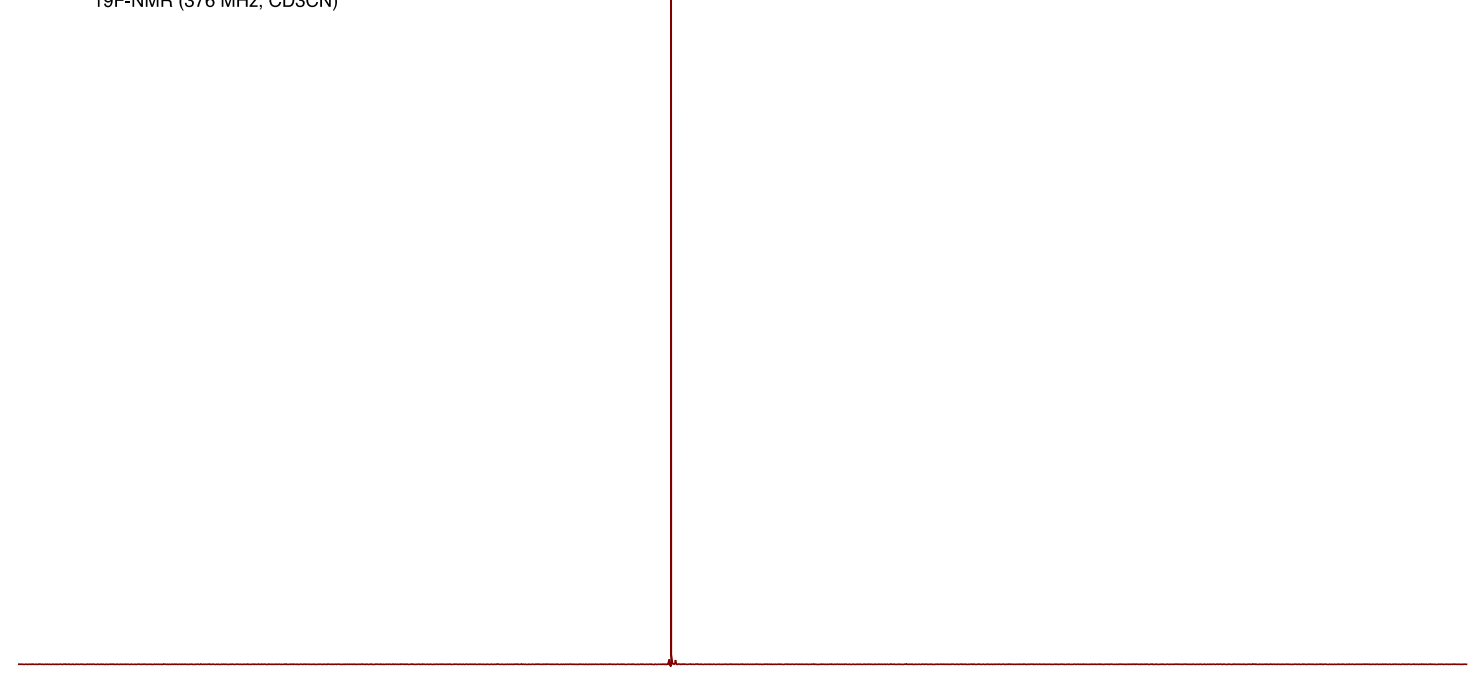

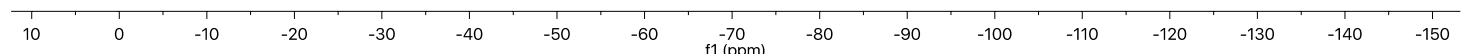



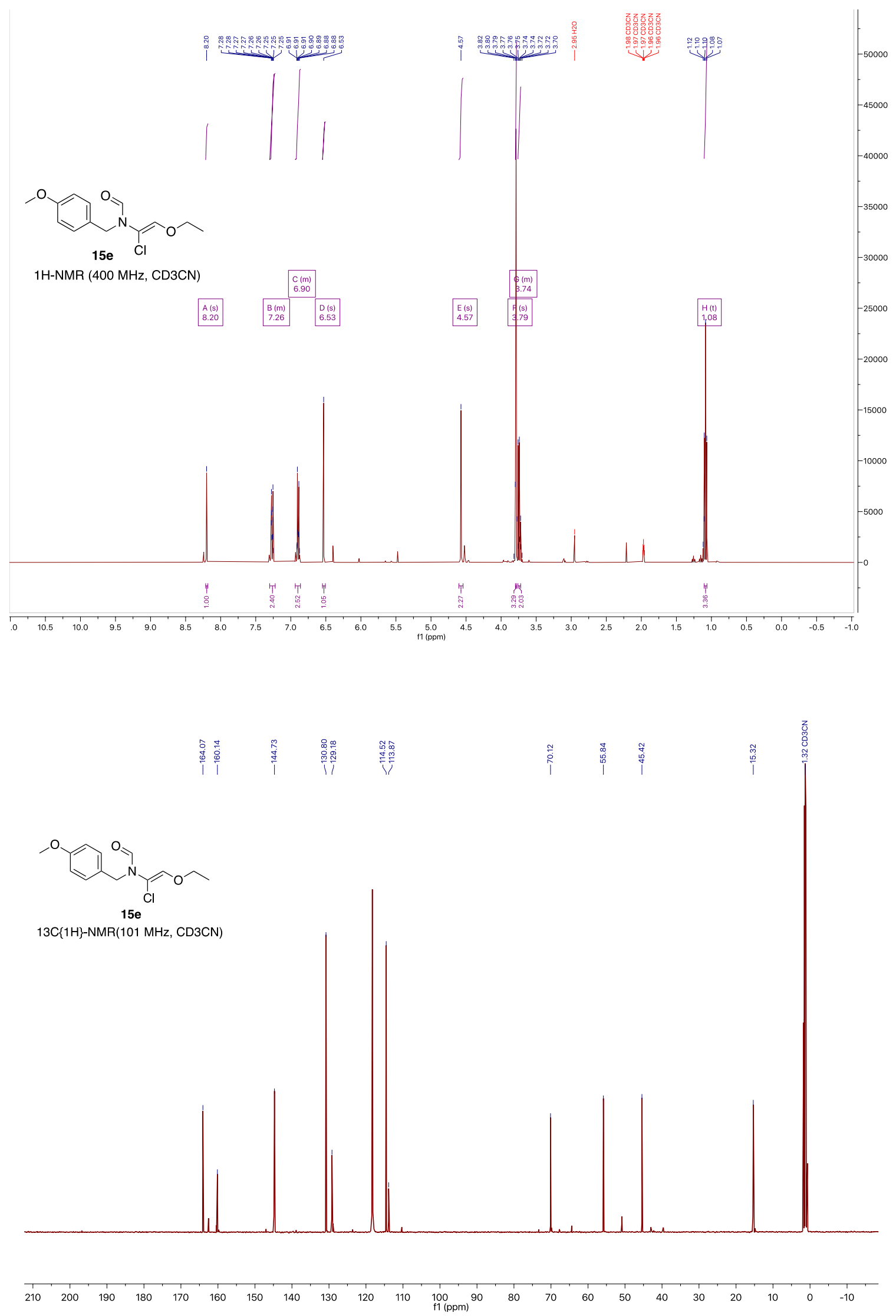

S2. 

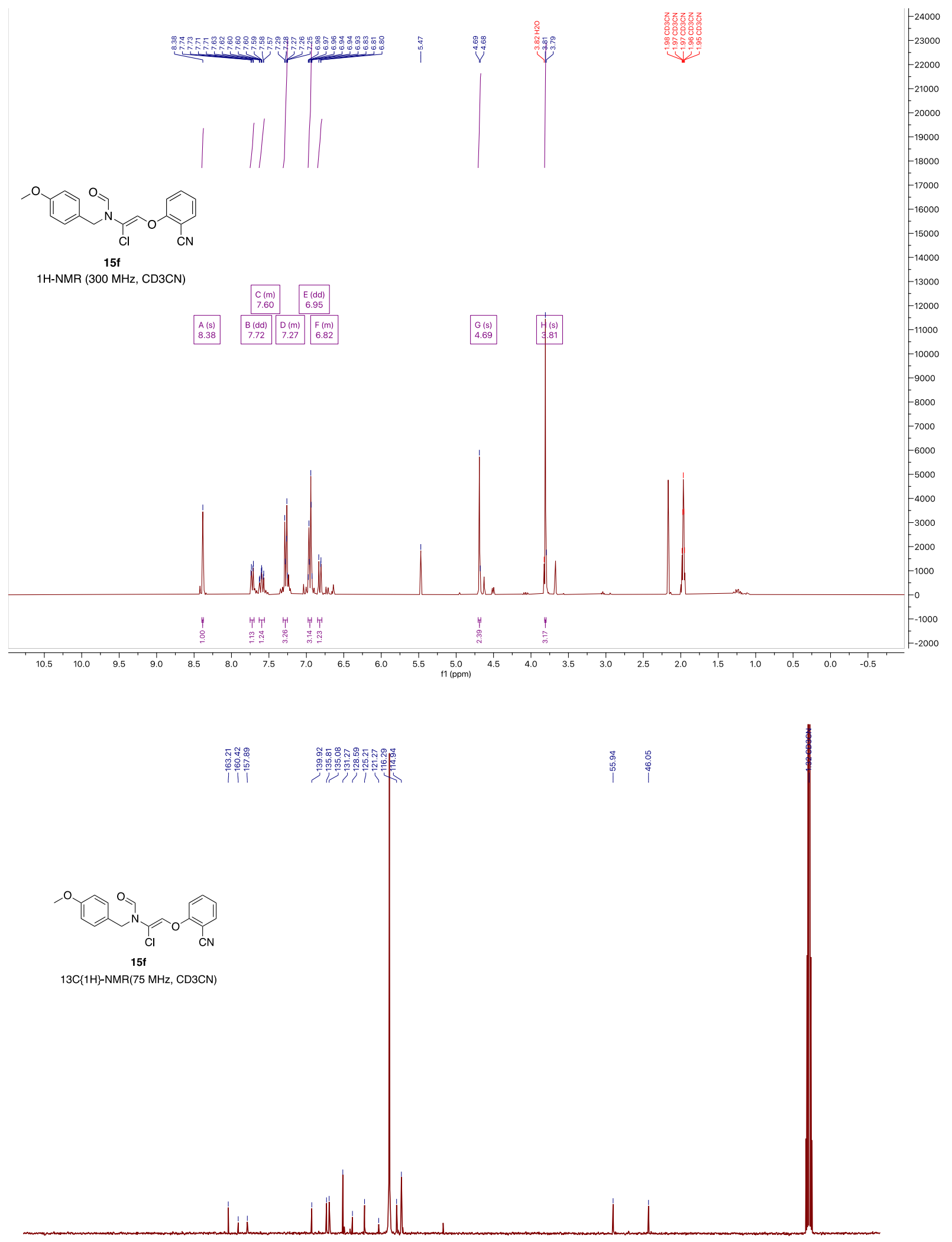


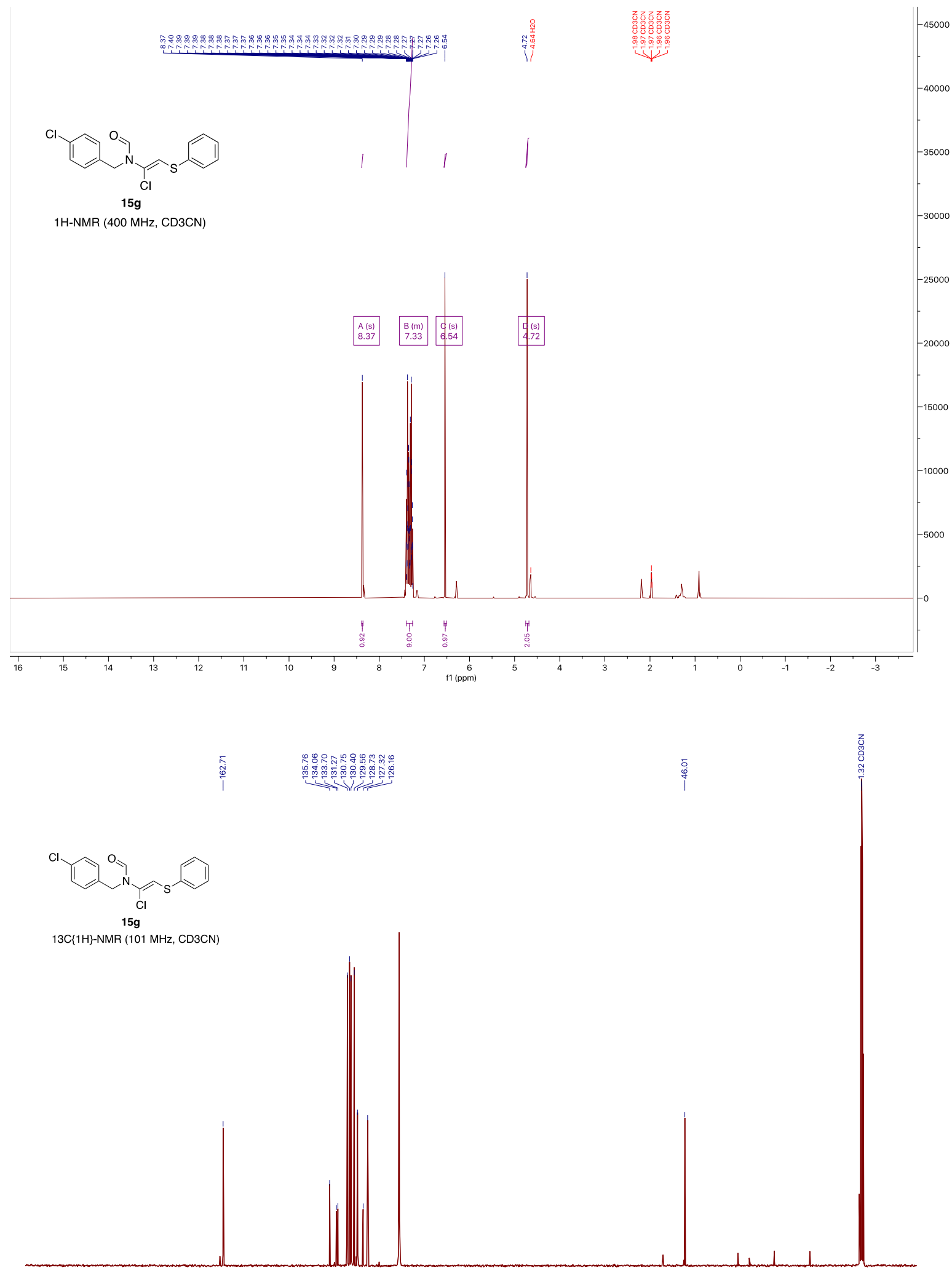

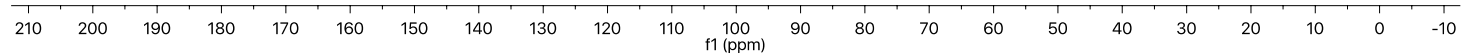



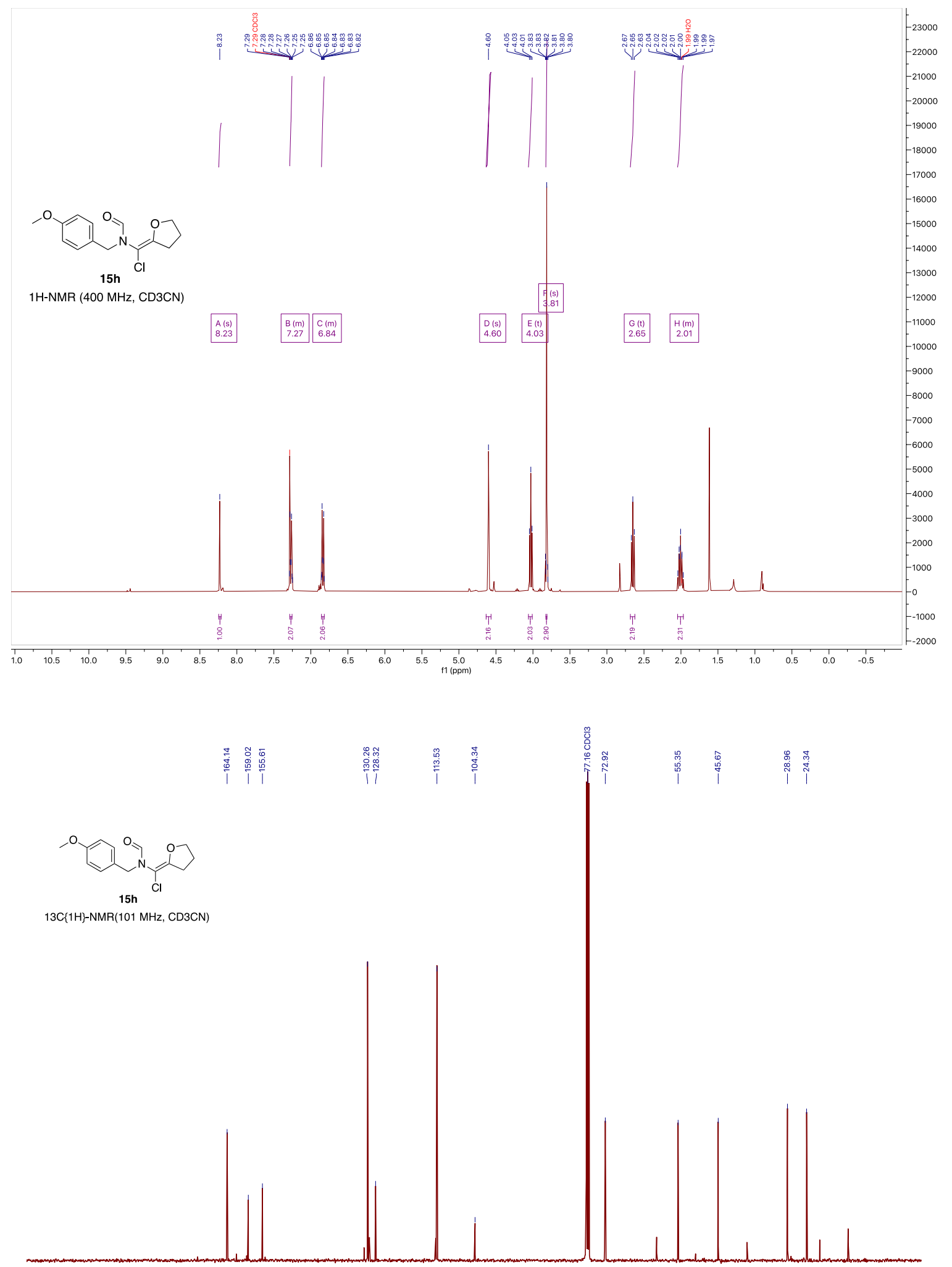

\begin{tabular}{lllllllllllllllllllll}
\hline 210 & 200 & 190 & 180 & 170 & 160 & 150 & 140 & 130 & 120 & $\underset{\mathrm{f} 1(\mathrm{ppm})}{110}$ & 90 & 80 & 70 & 60 & 50 & 40 & 30 & 20 & 10 & 0
\end{tabular} 

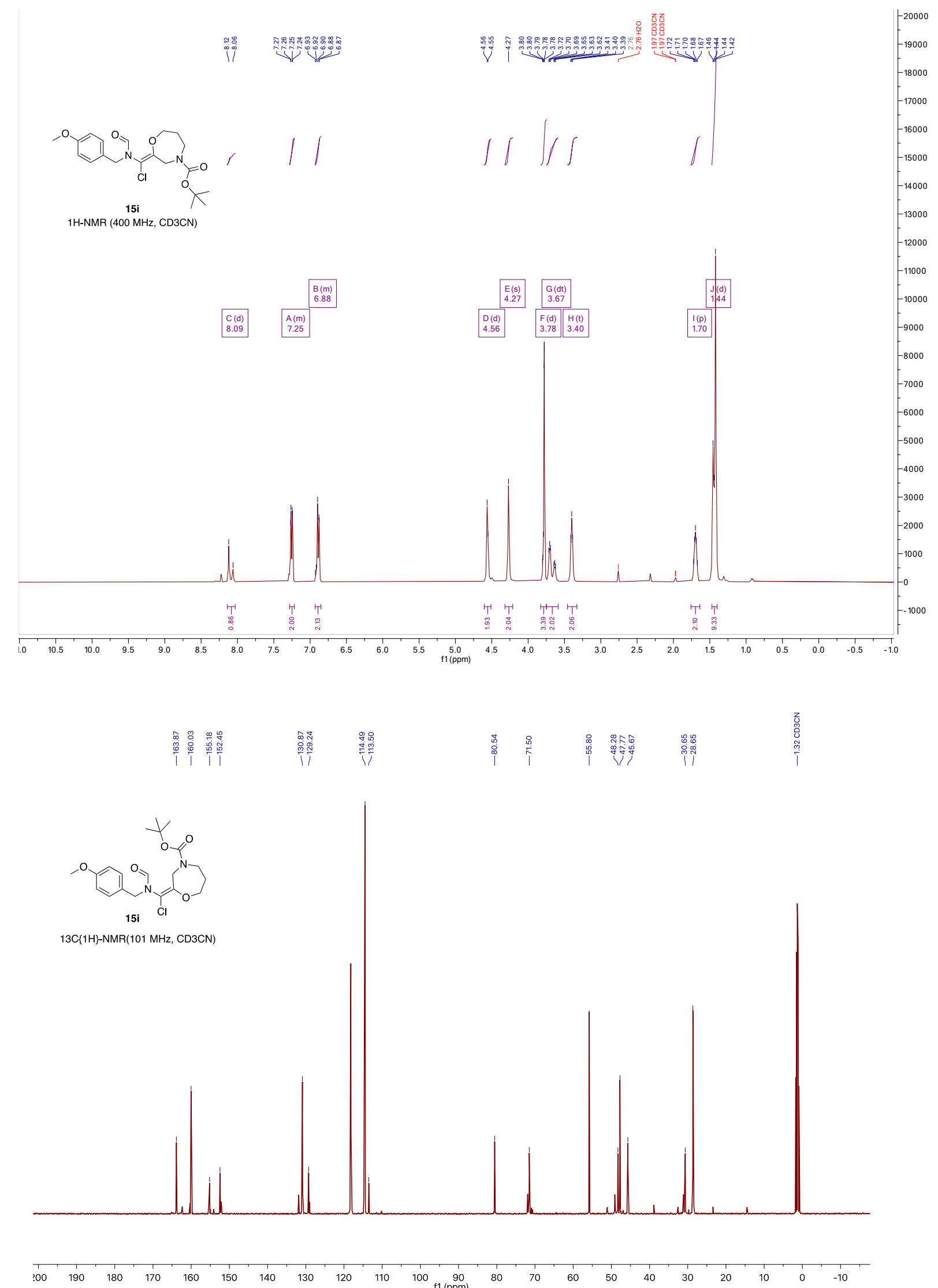

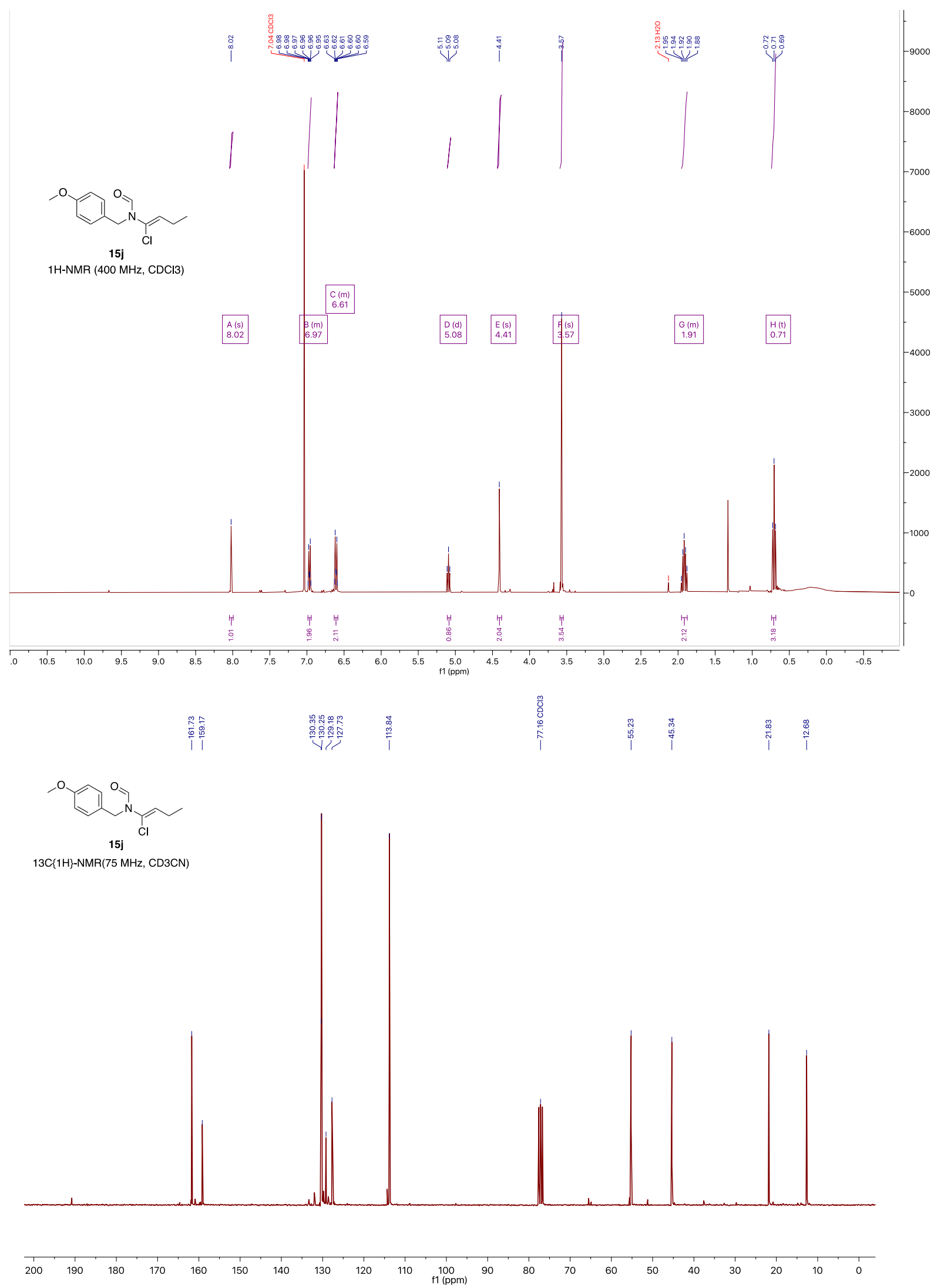

S3 

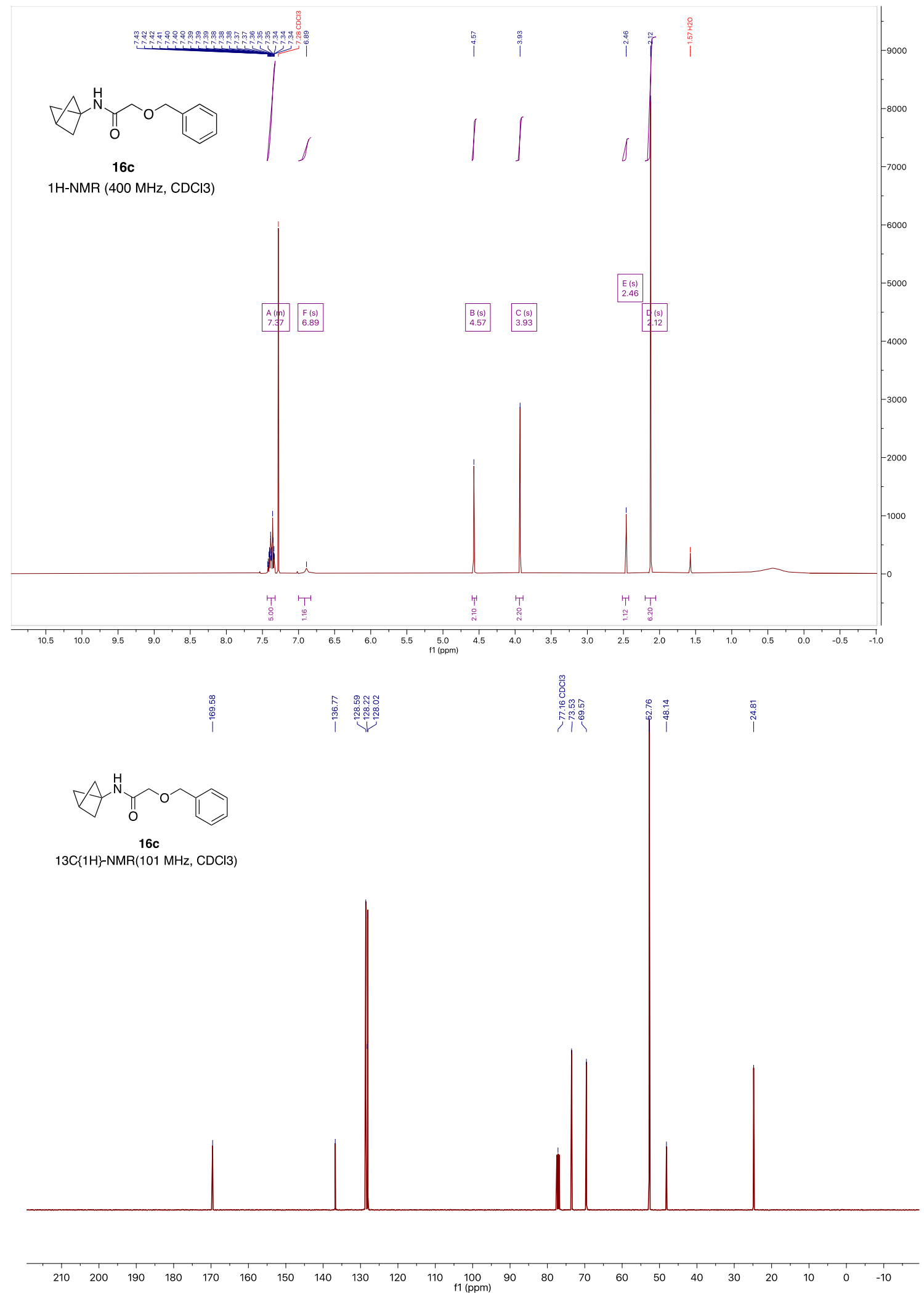


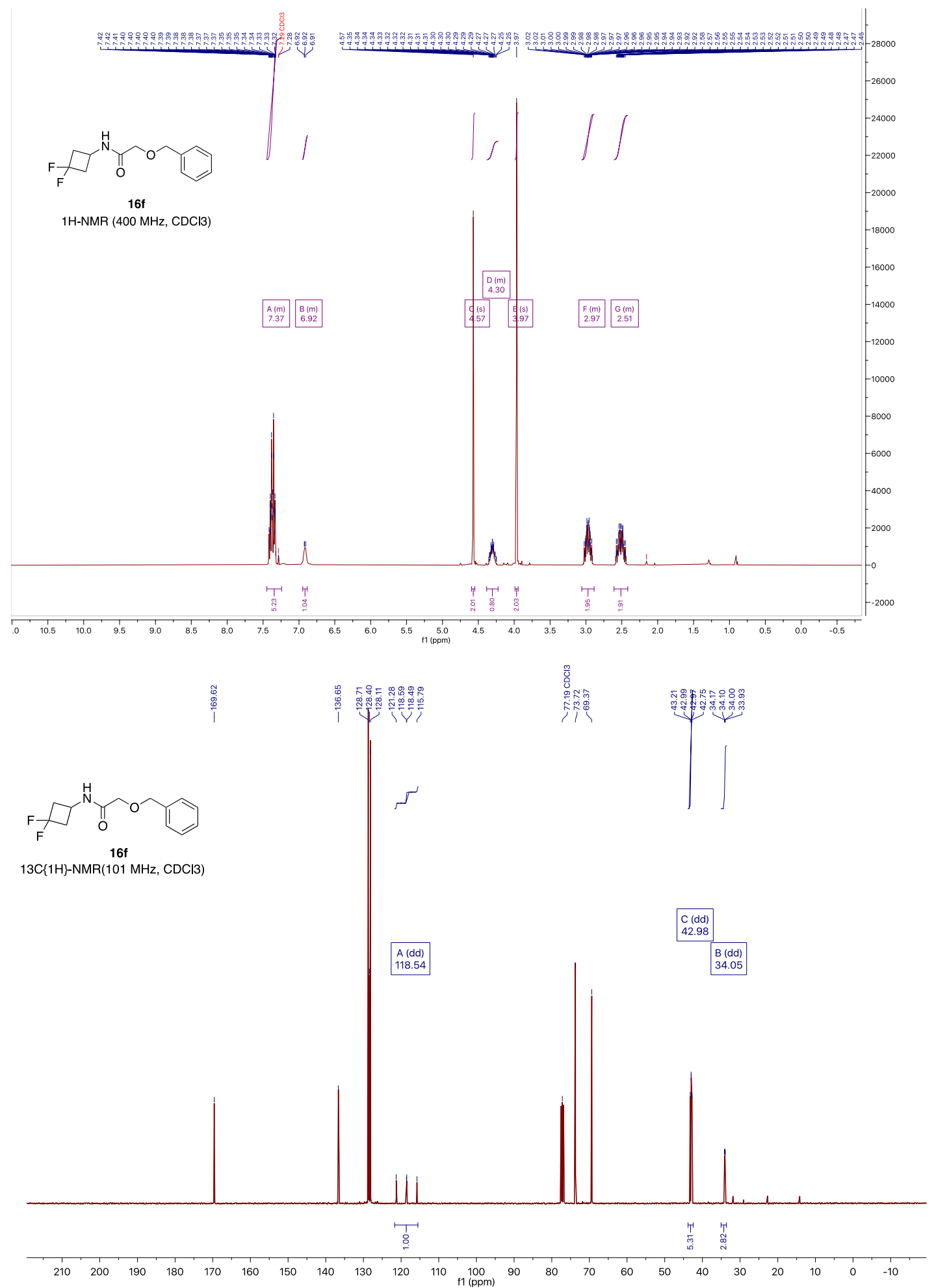



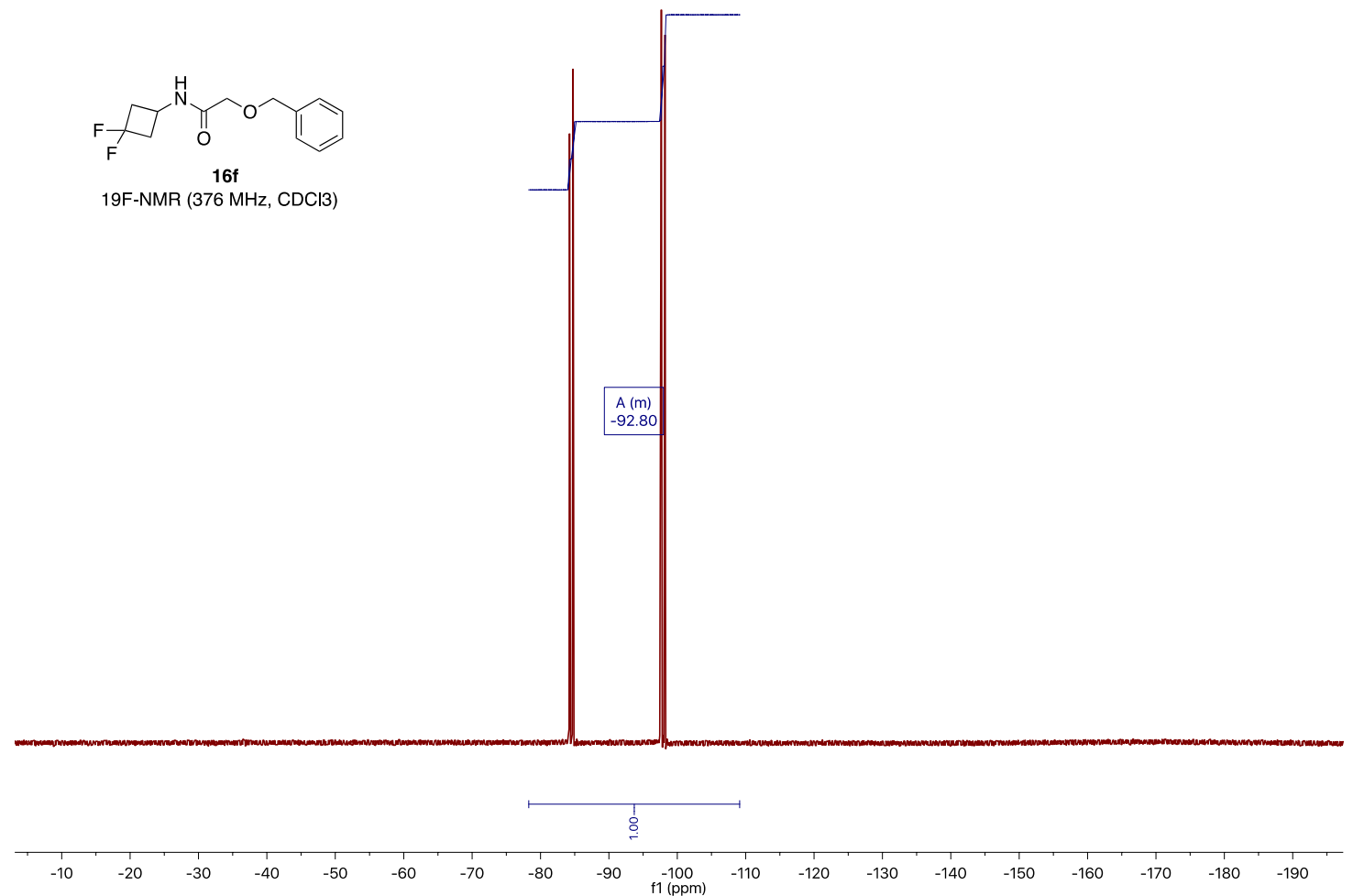

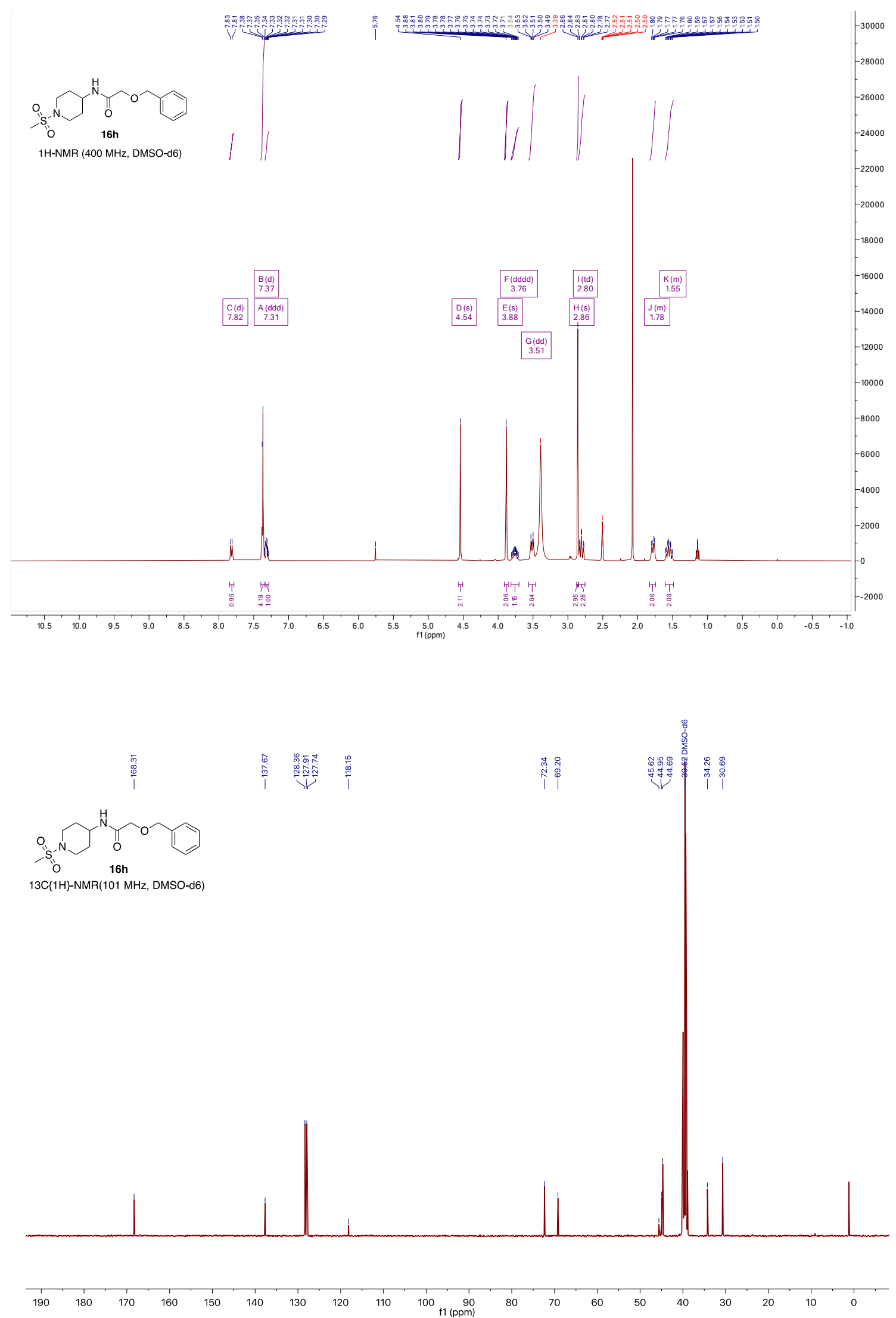


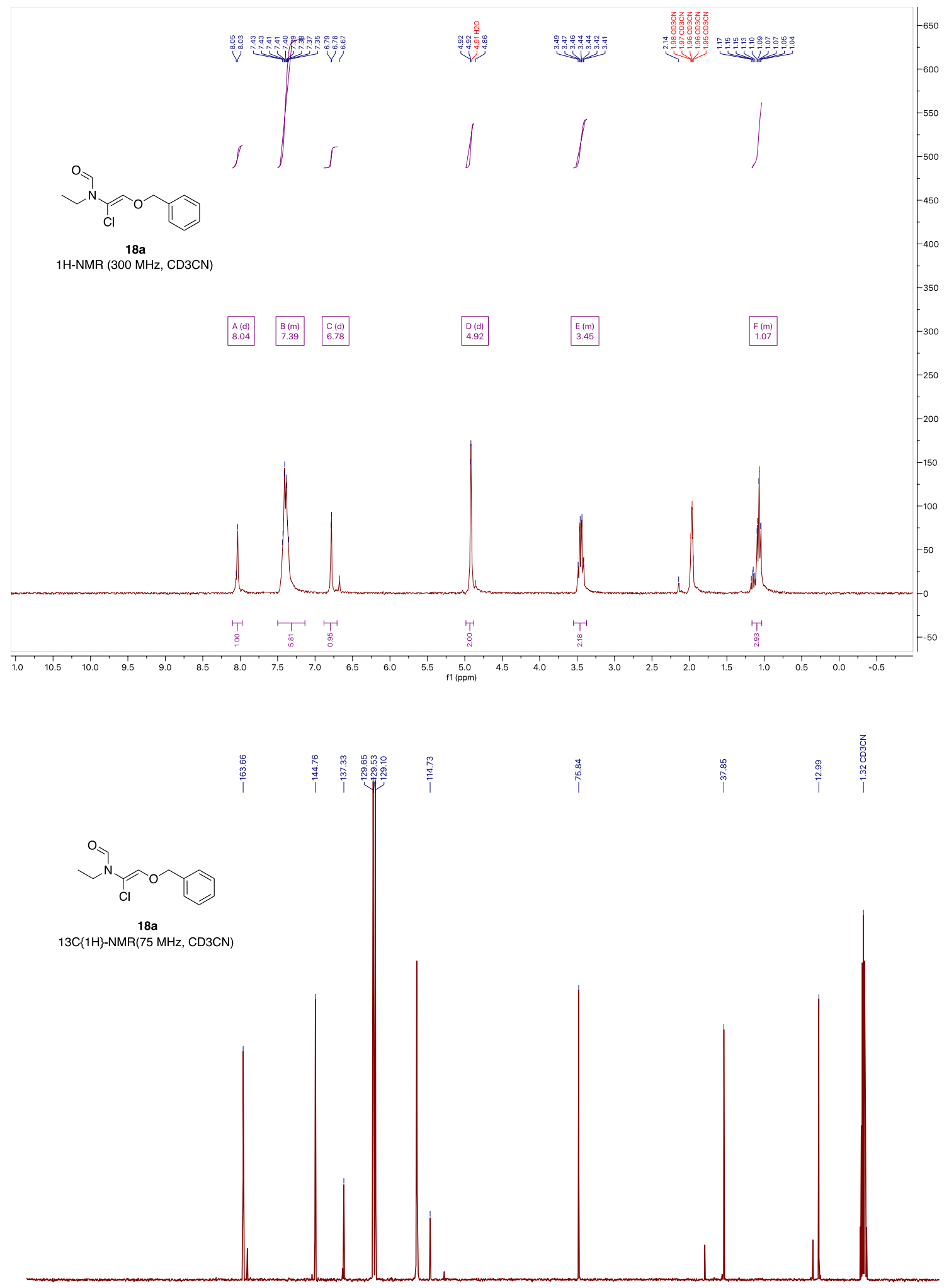

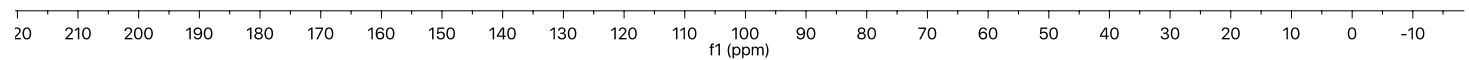



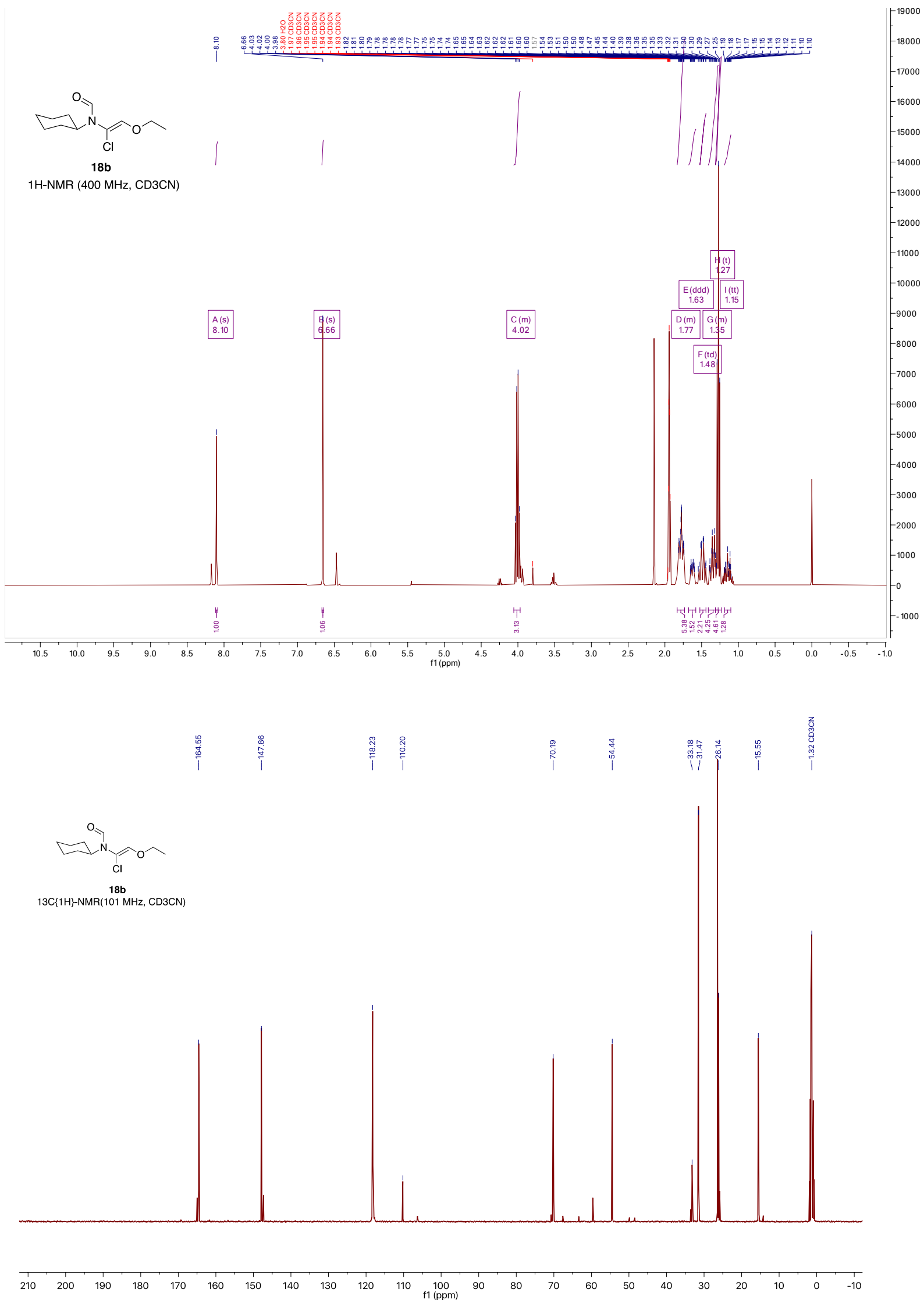

S3 


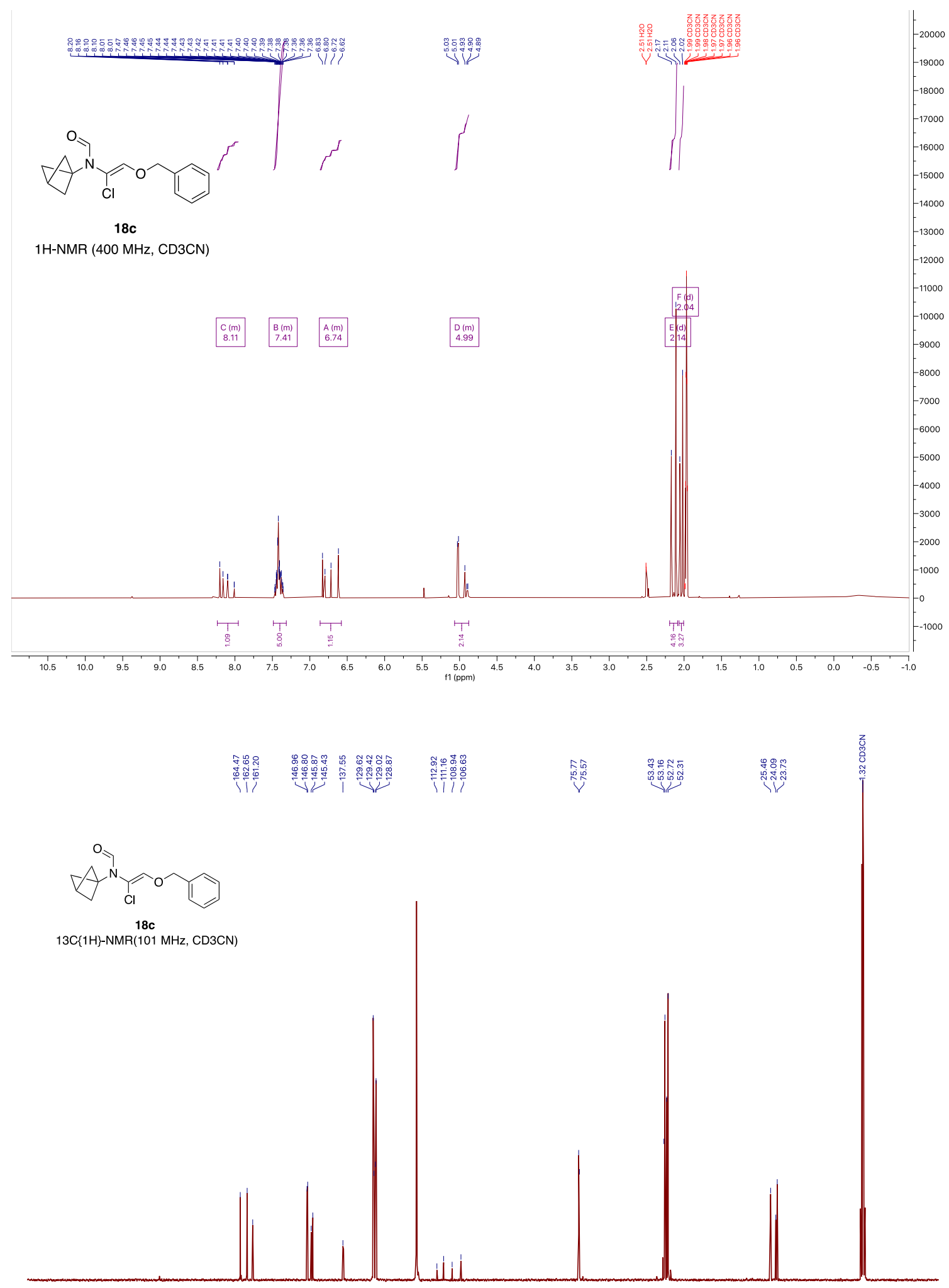

\begin{tabular}{lllllllllllllllllllllllllllllllll}
\hline 20 & 210 & 200 & 190 & 180 & 170 & 160 & 150 & 140 & 130 & 120 & 110 & 100 & 90 & 80 & 70 & 60 & 50 & 40 & 30 & 20 & 10 & 0 & -10
\end{tabular} 

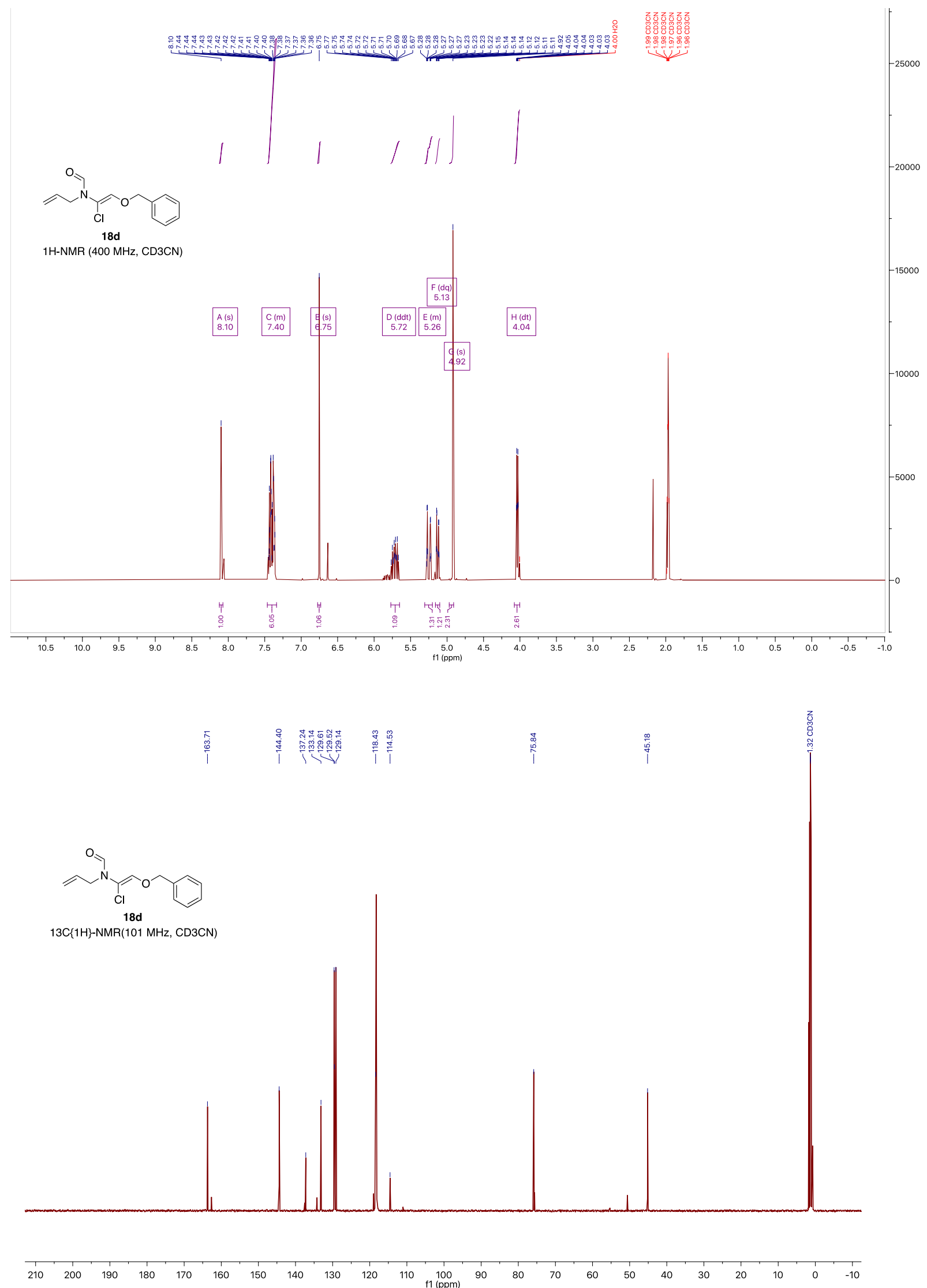


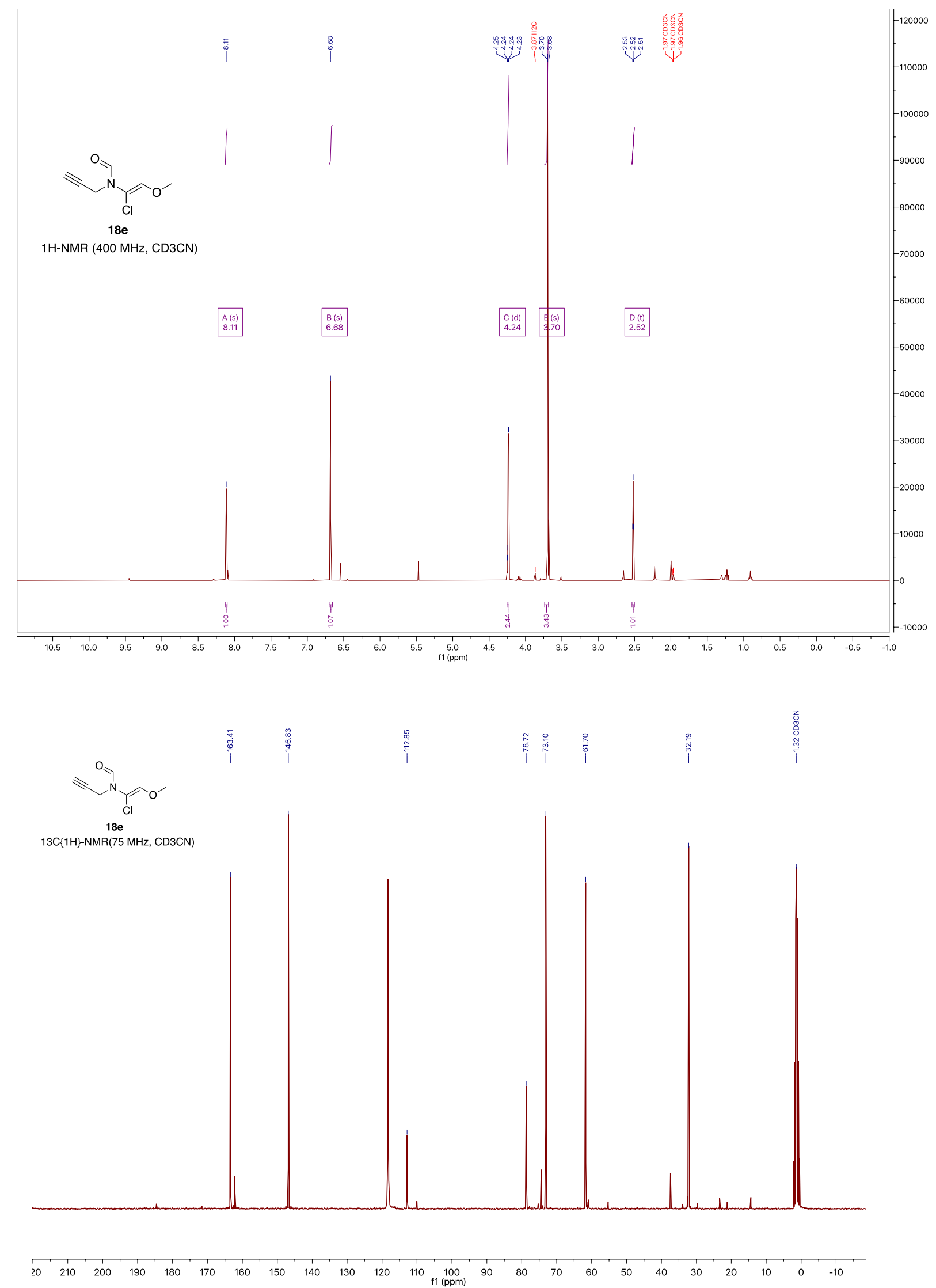



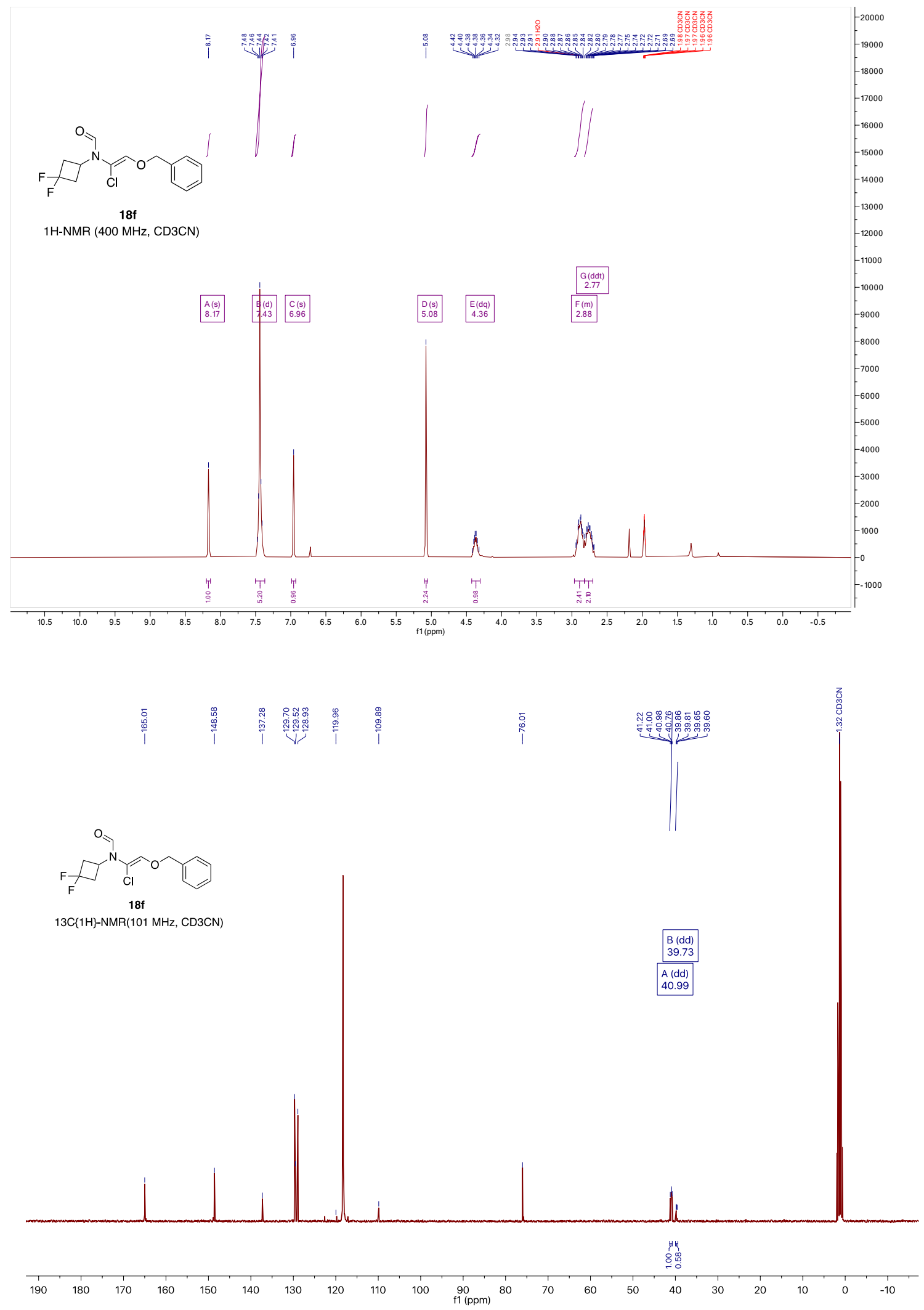

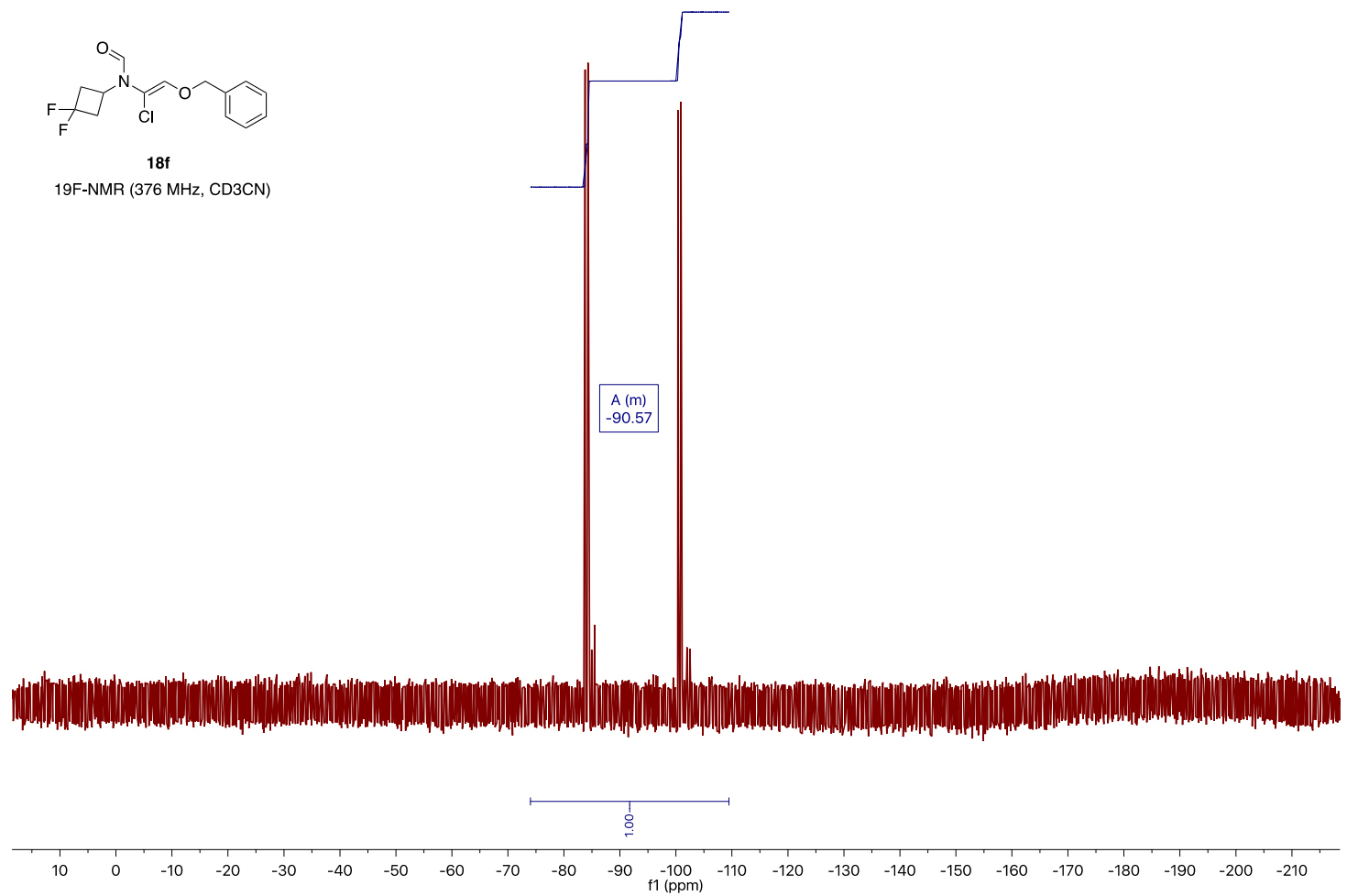

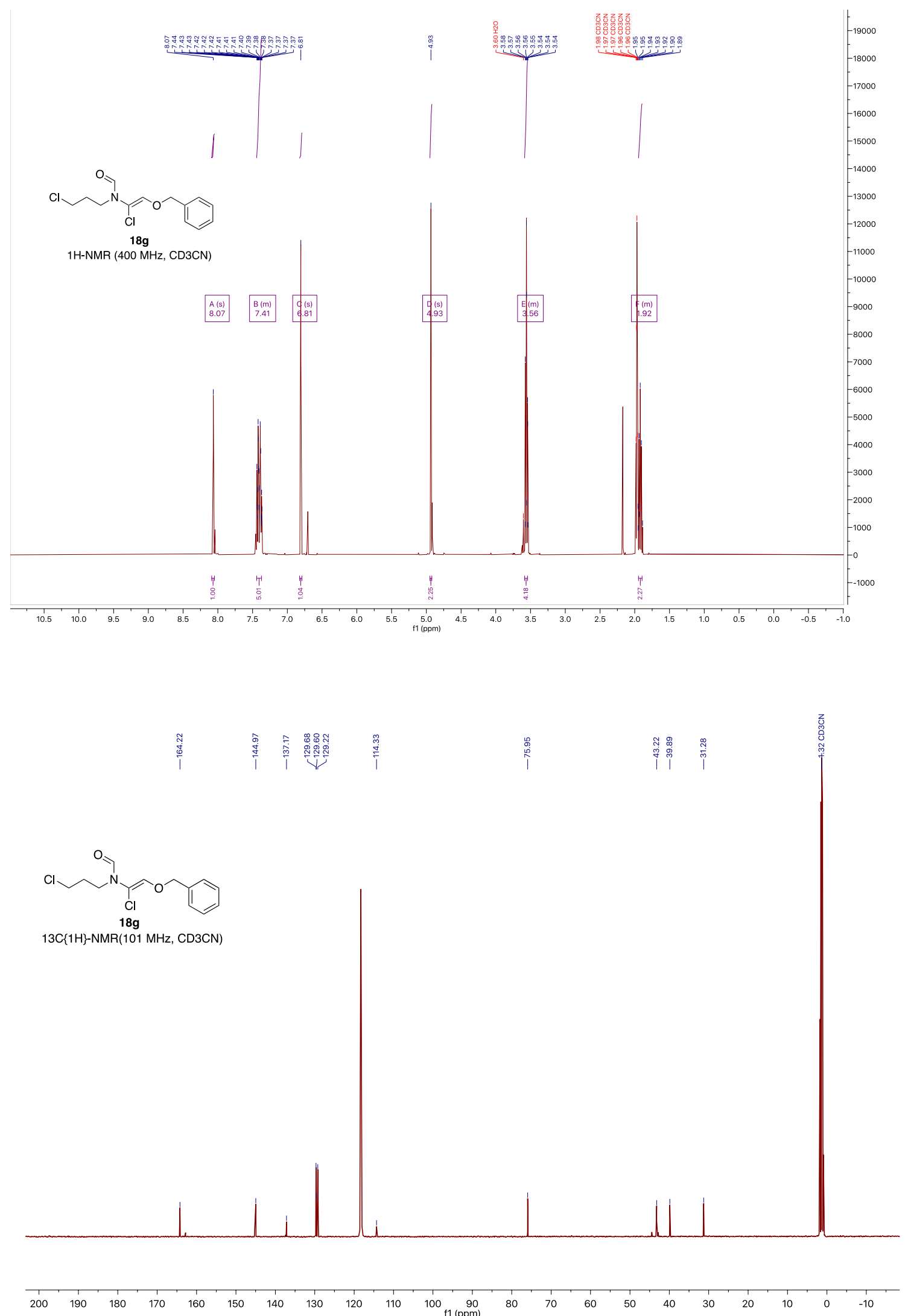


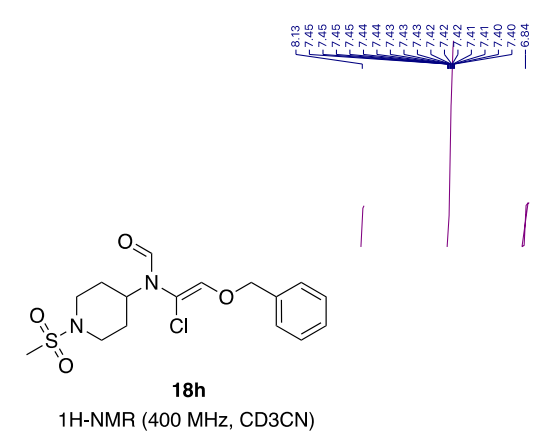

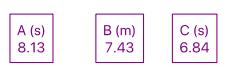
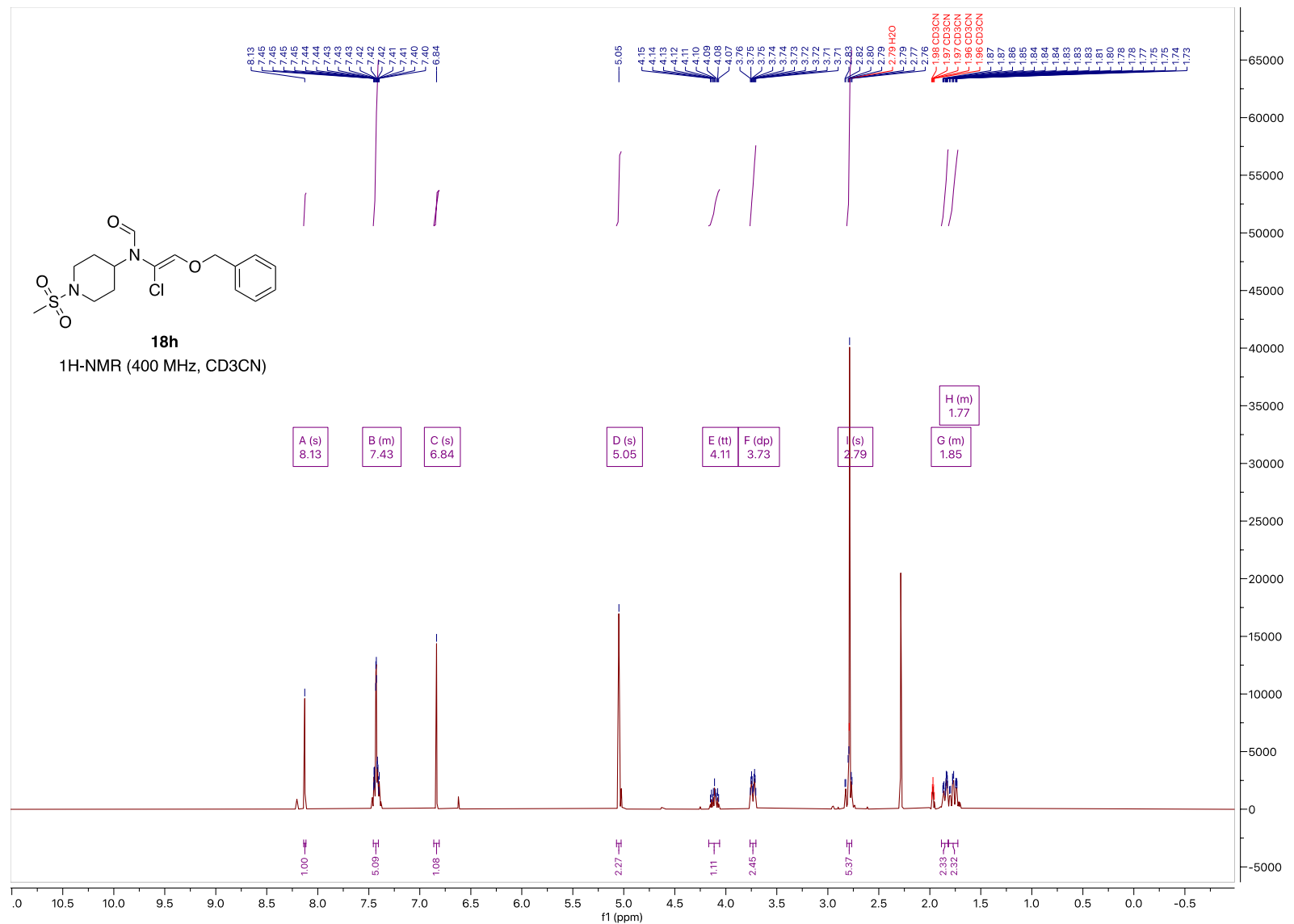

0500
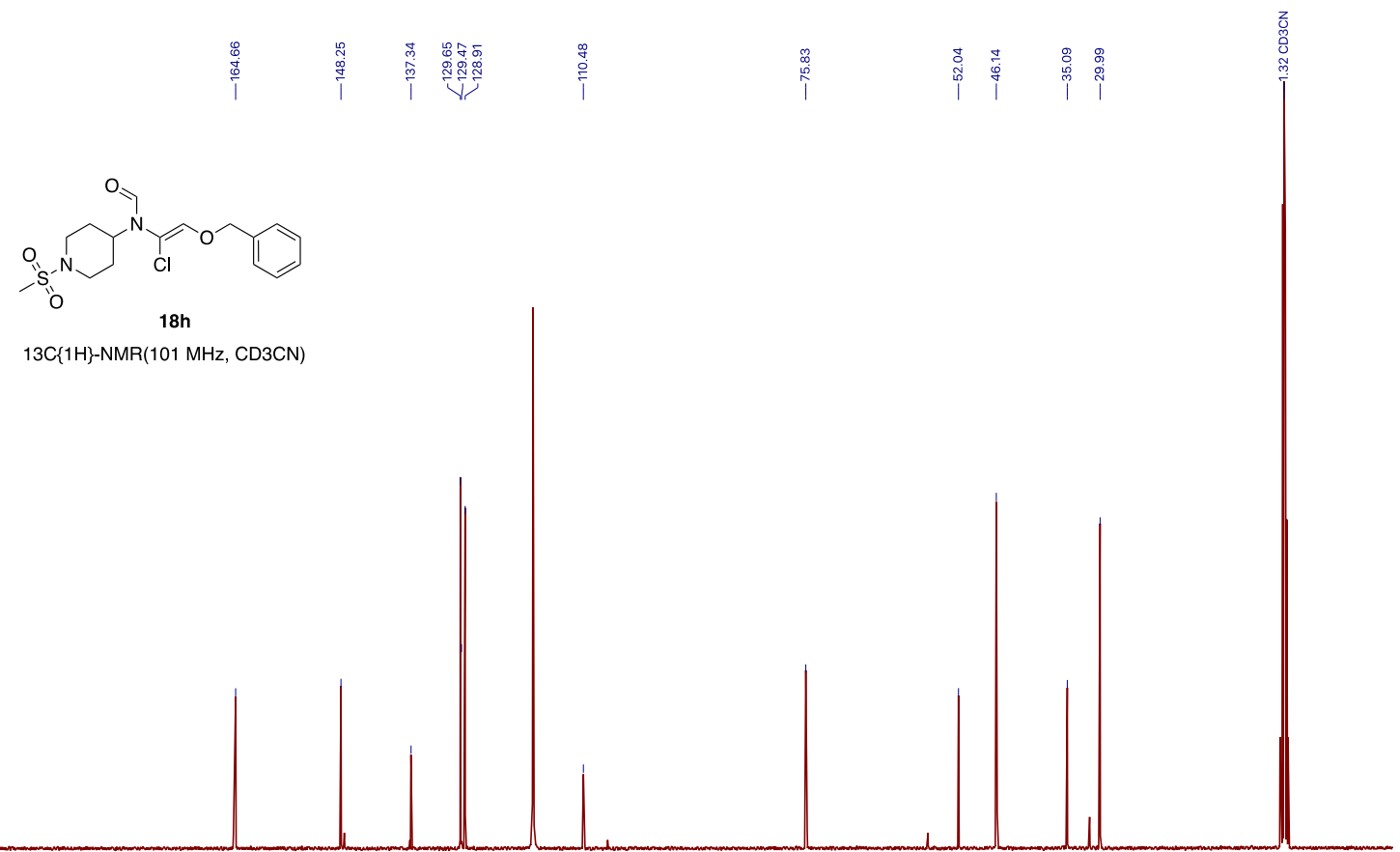

$$
200
$$

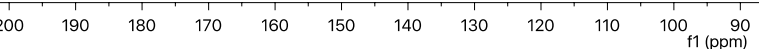



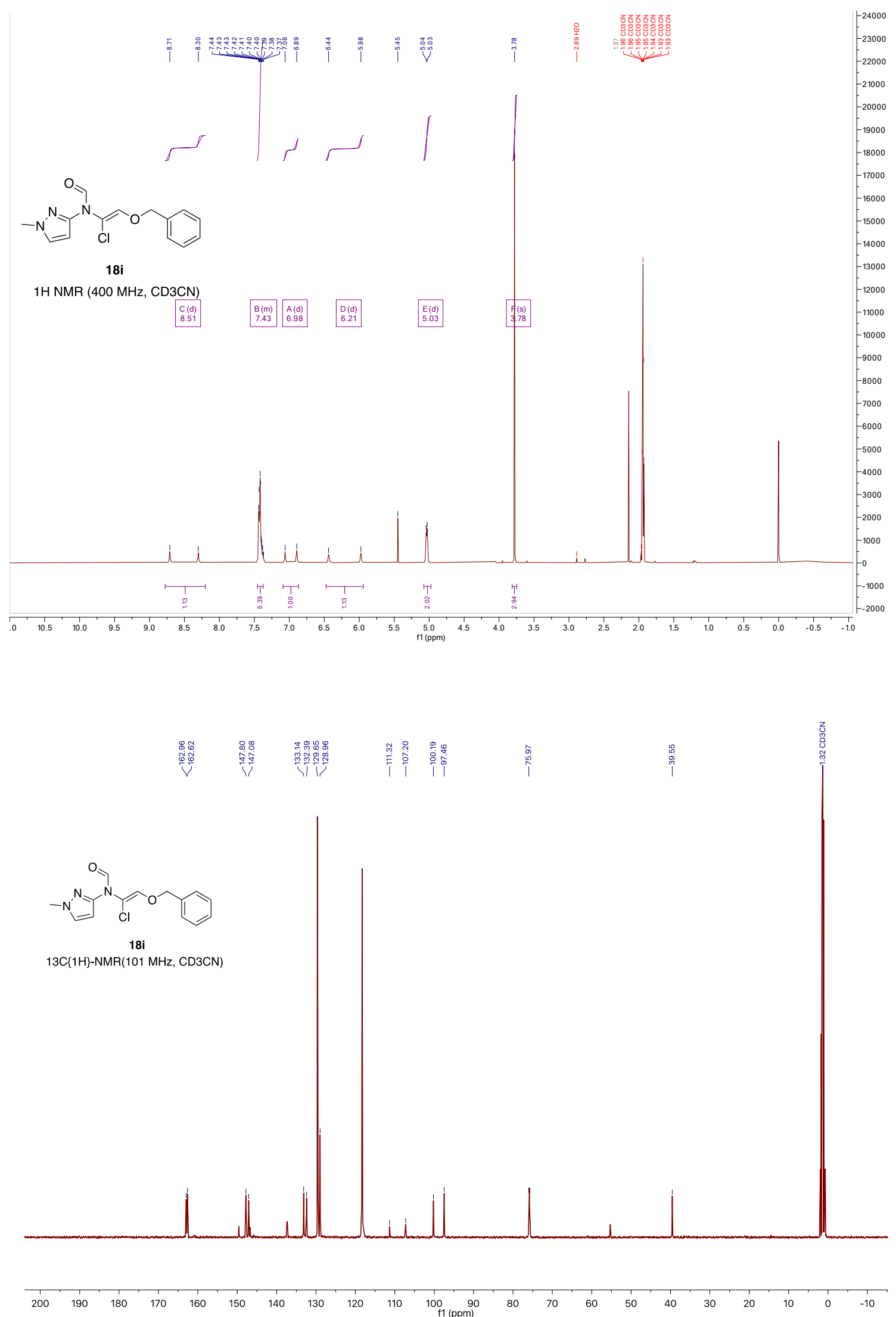

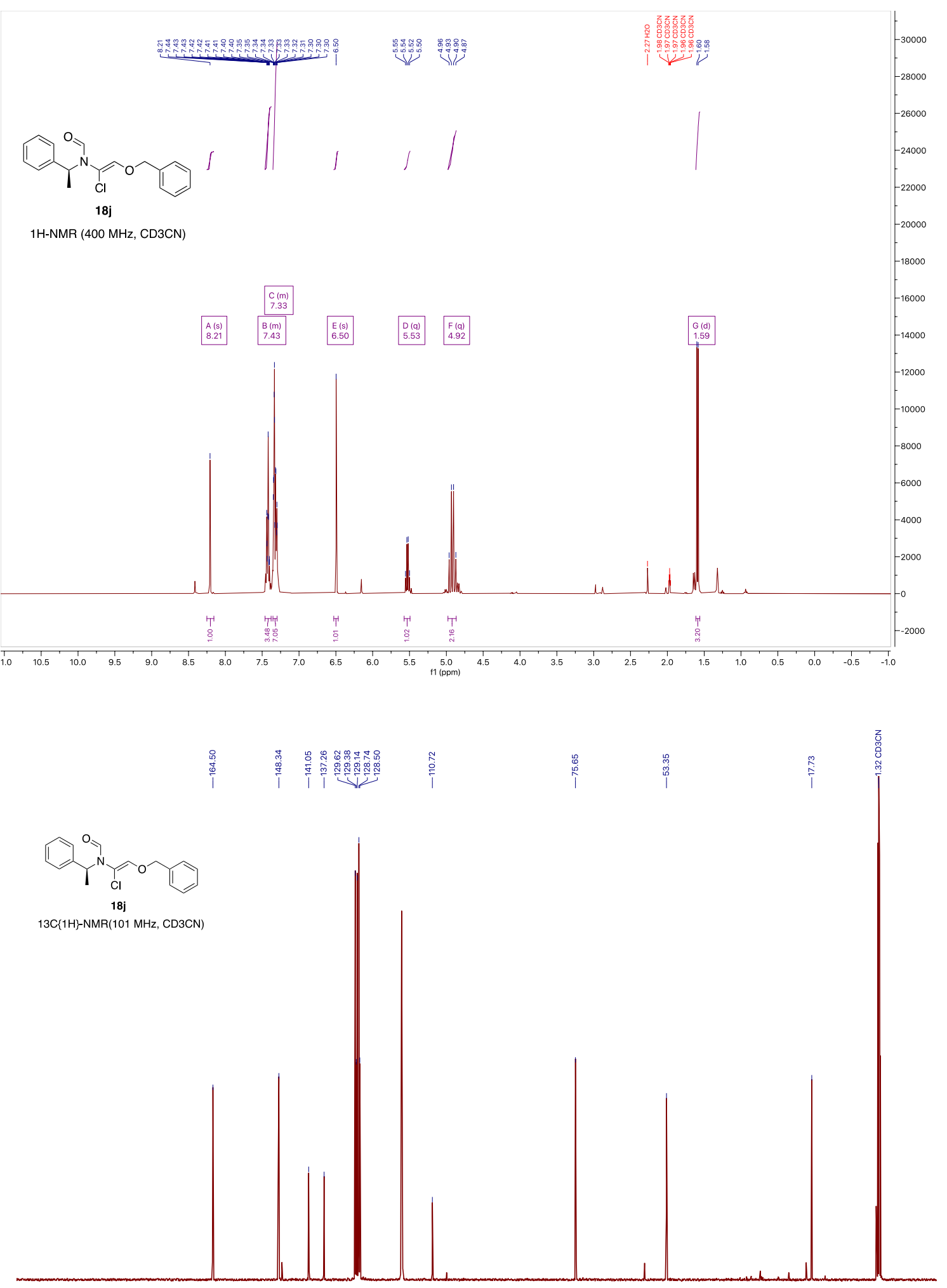

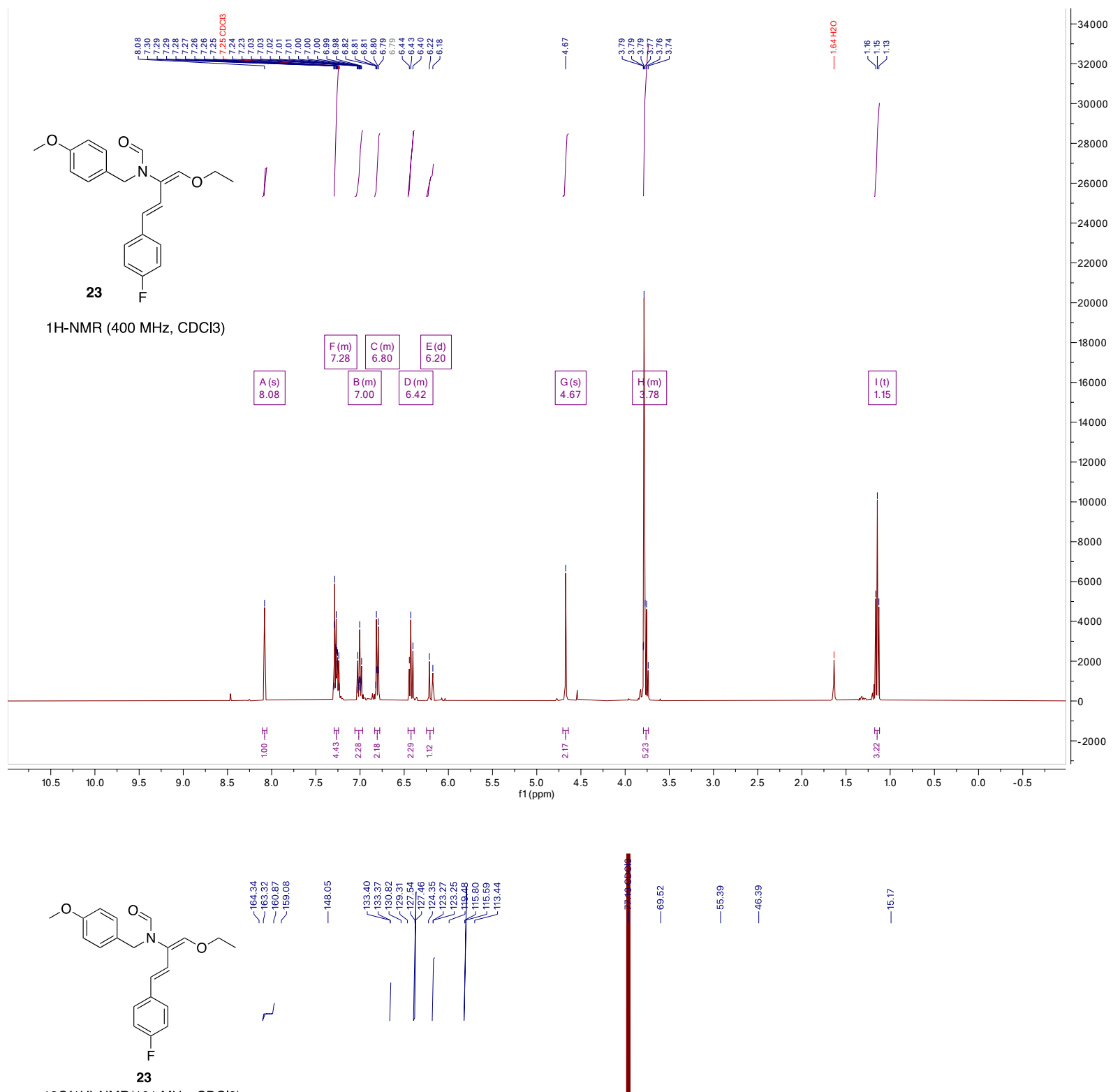

13C $\{1 \mathrm{H}\}-\mathrm{NMR}(101 \mathrm{MHz}, \mathrm{CDCl} 3)$

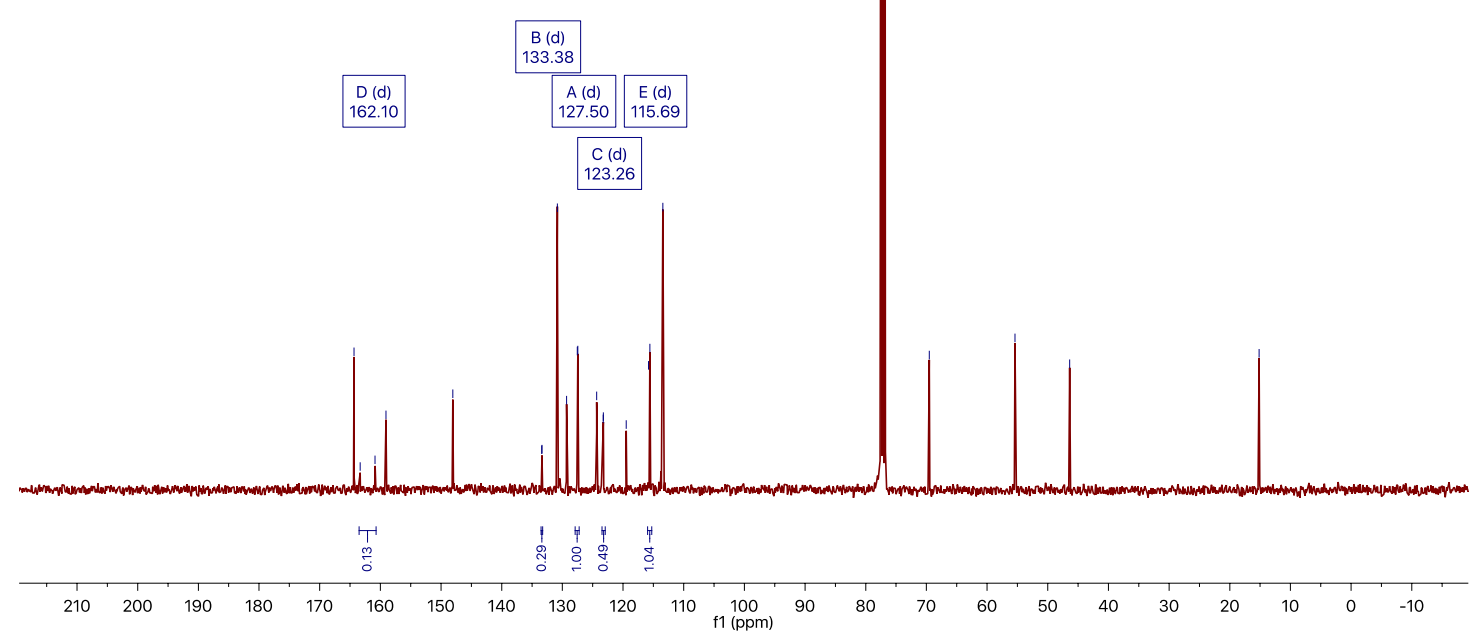




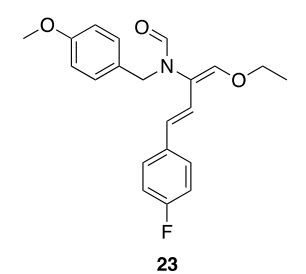

19F-NMR (376 MHz, CDCl3)

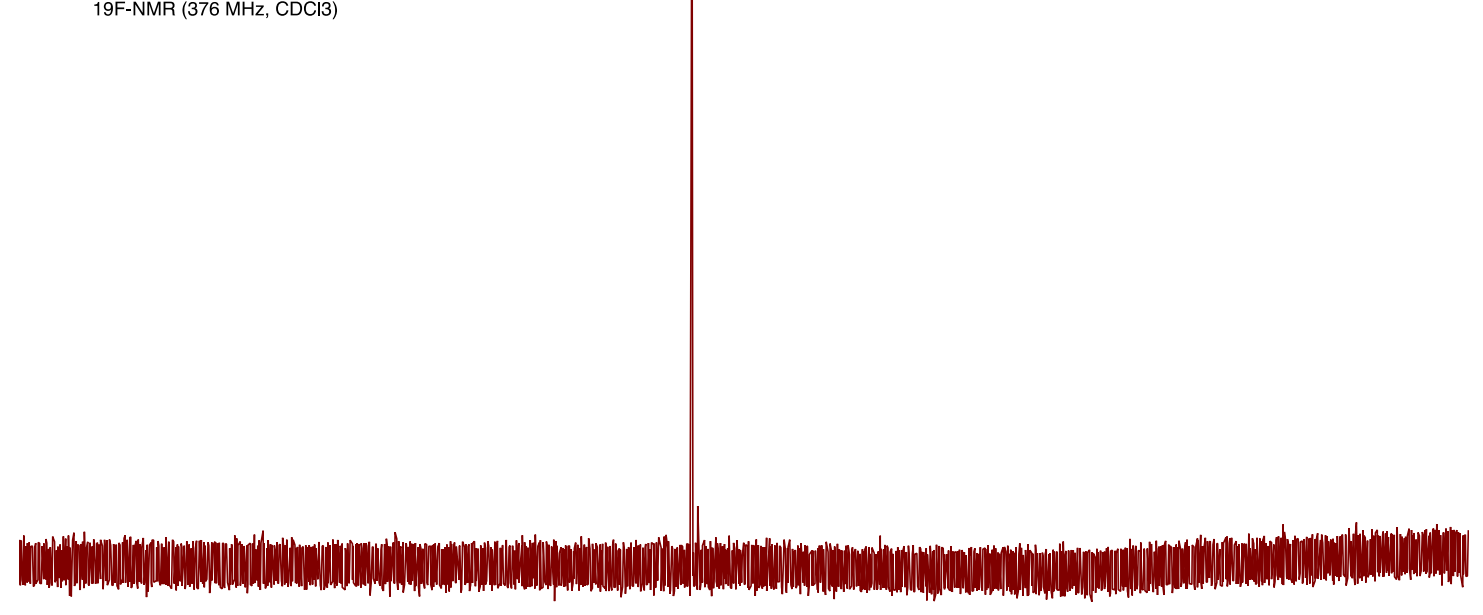

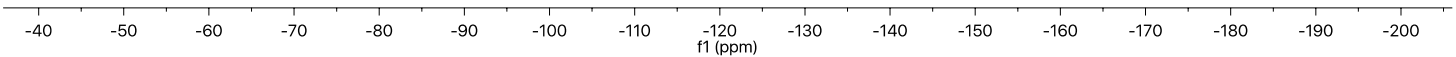



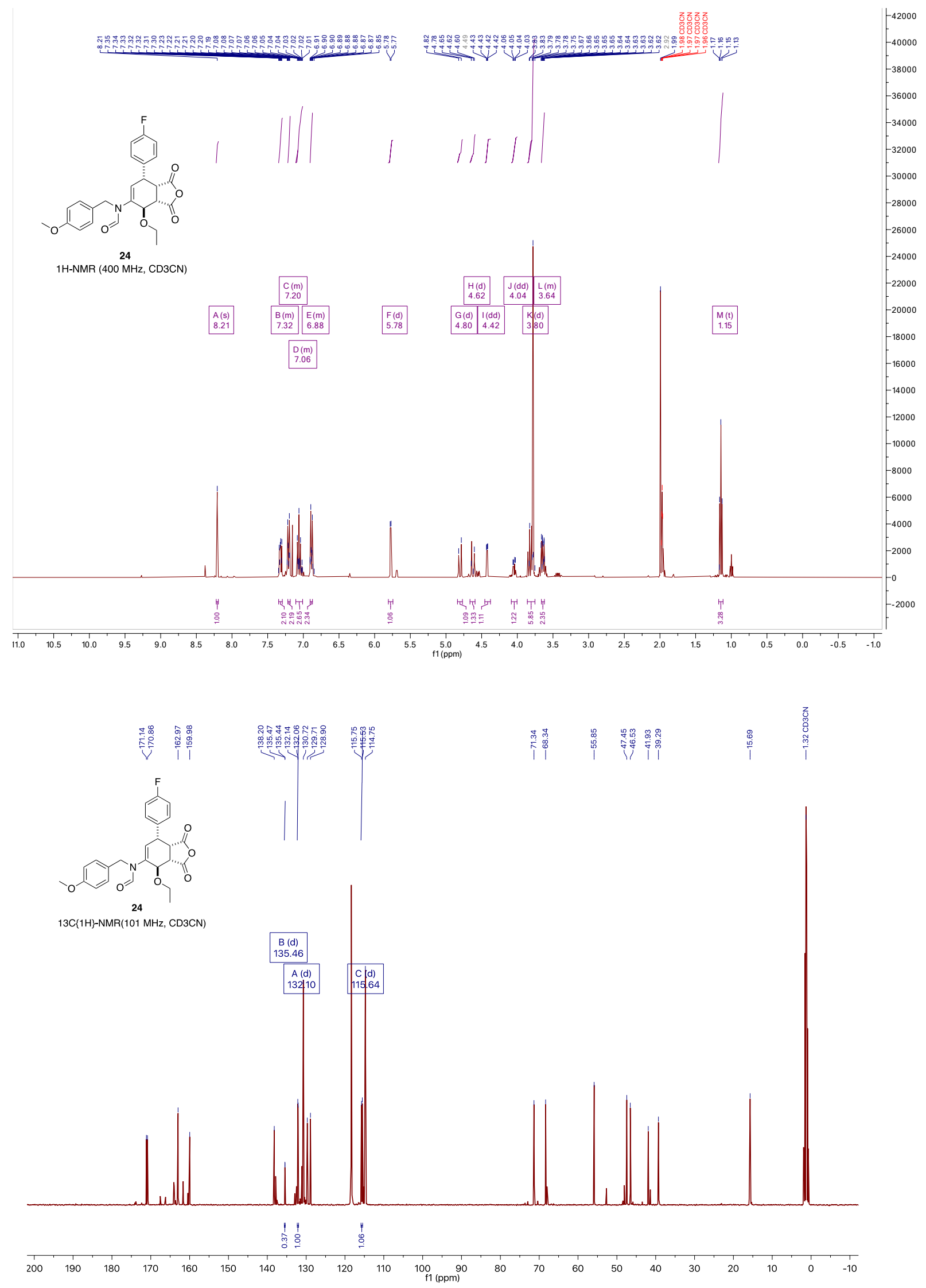


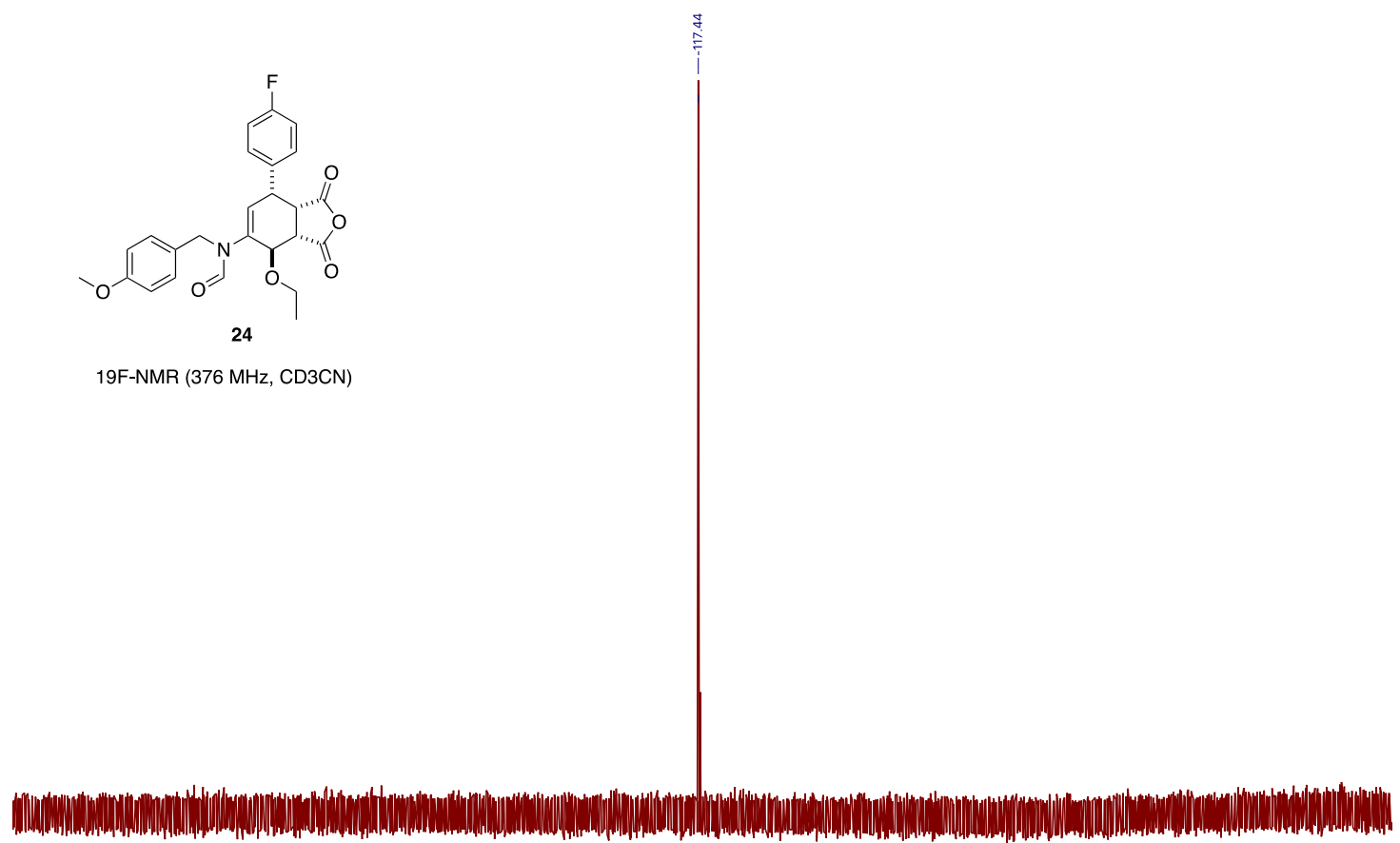

\begin{tabular}{|c|c|c|c|c|c|c|c|c|c|c|c|c|}
\hline-4 & \multicolumn{2}{|c|}{-50} & -60 & -70 & \multicolumn{2}{|c|}{-80} & -9 & $1\left(\begin{array}{r}-12 \\
(\mathrm{ppm})\end{array}\right.$ & -13 & -140 & -160 & $-1 /$ \\
\hline
\end{tabular}




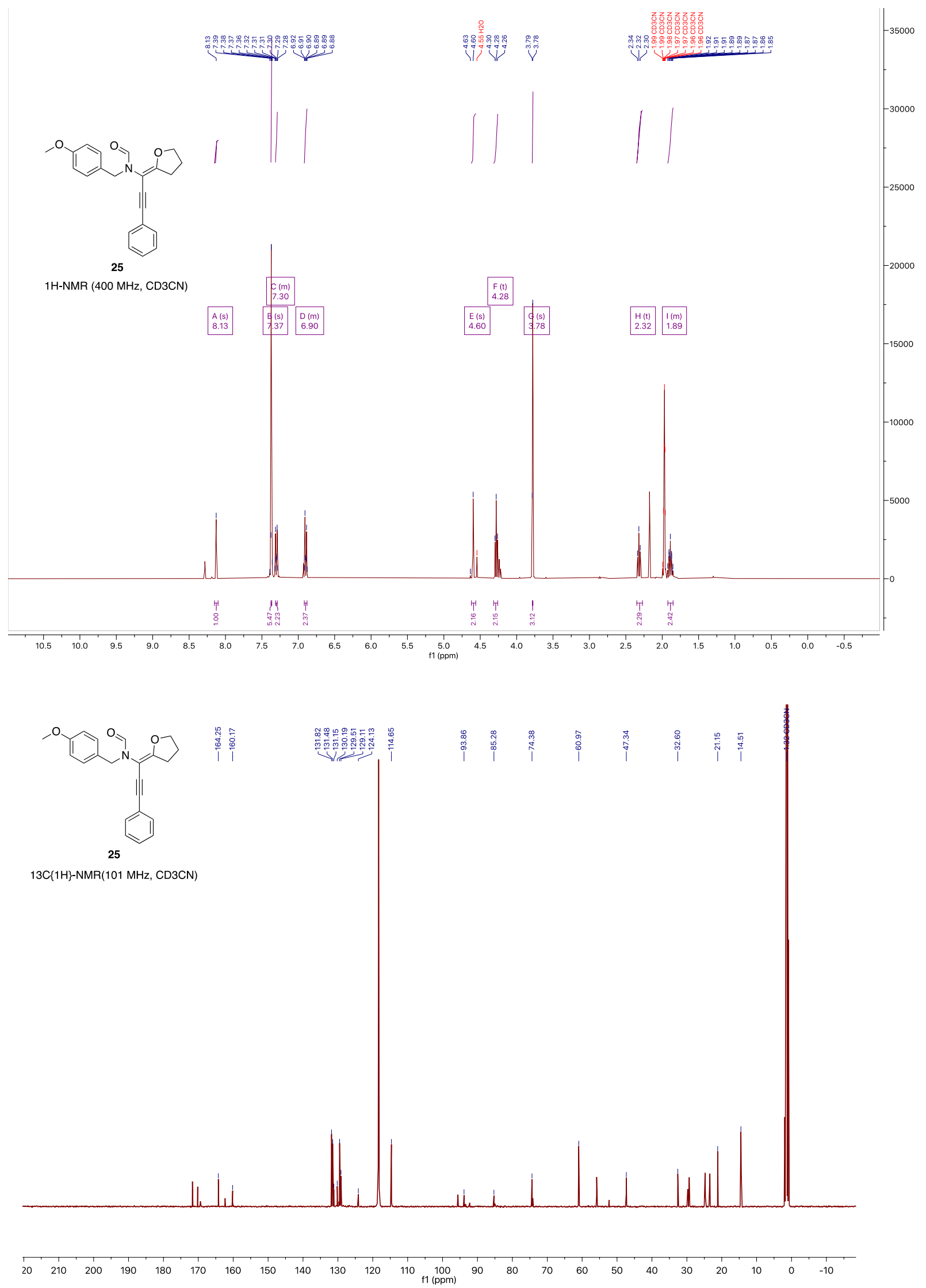



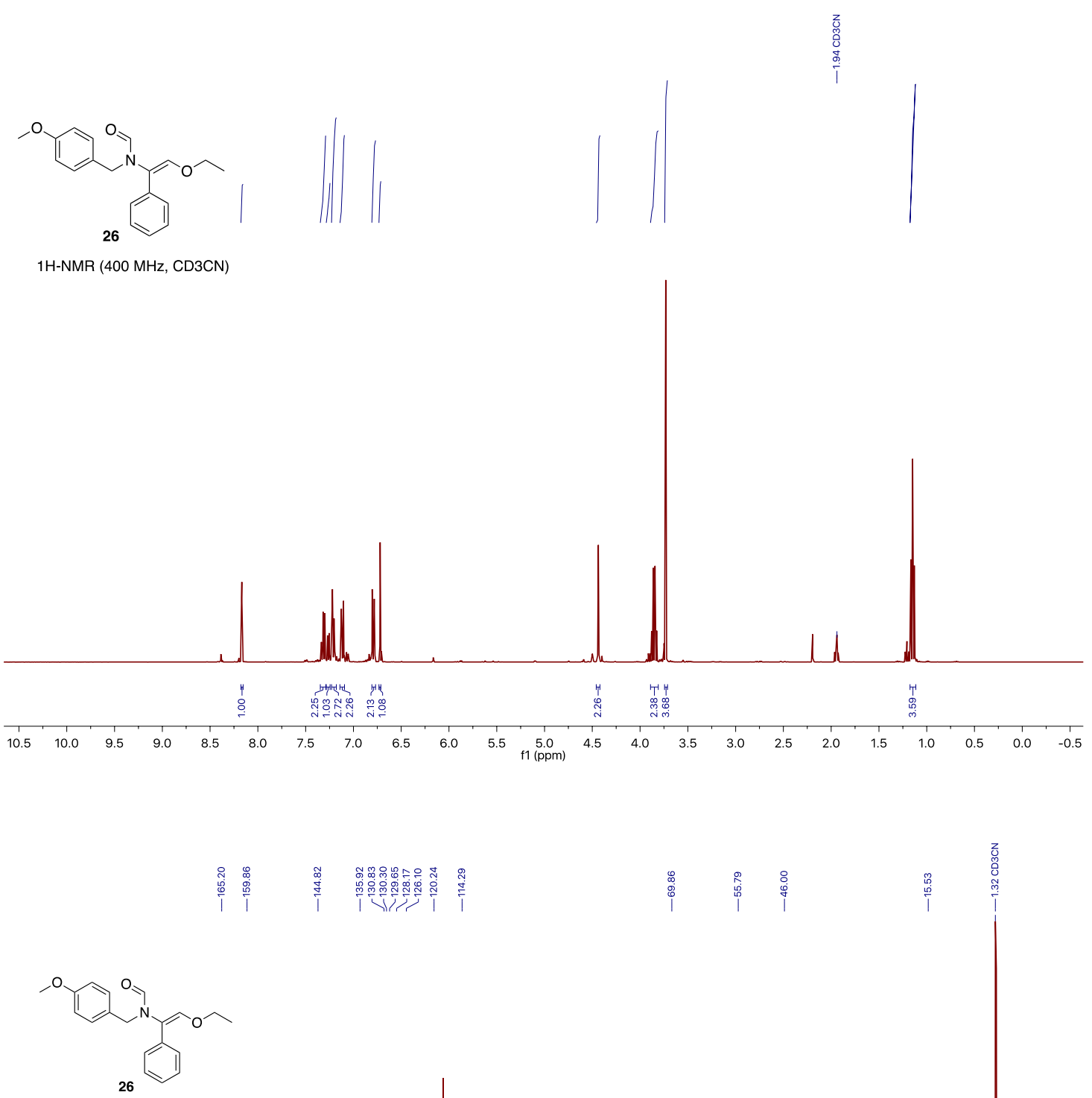

13C $\{1 \mathrm{H}\}-\mathrm{NMR}(101 \mathrm{MHz}, \mathrm{CD} 3 \mathrm{CN})$

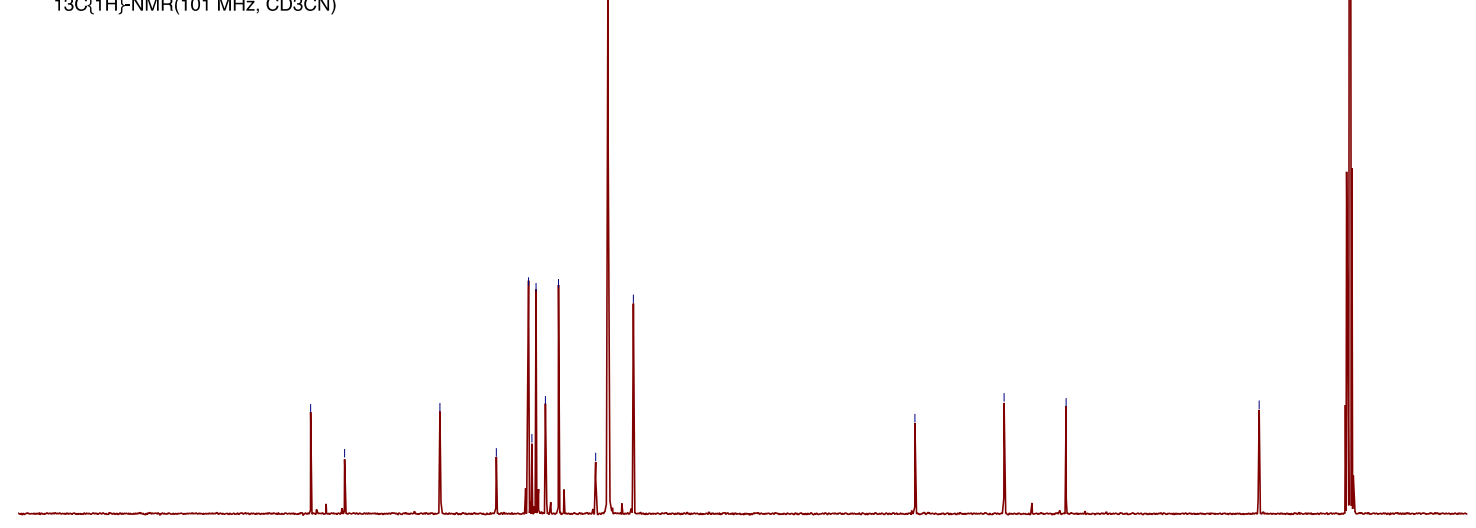

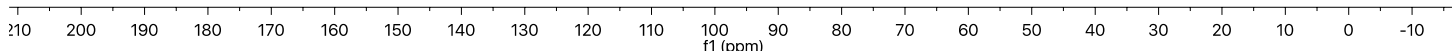



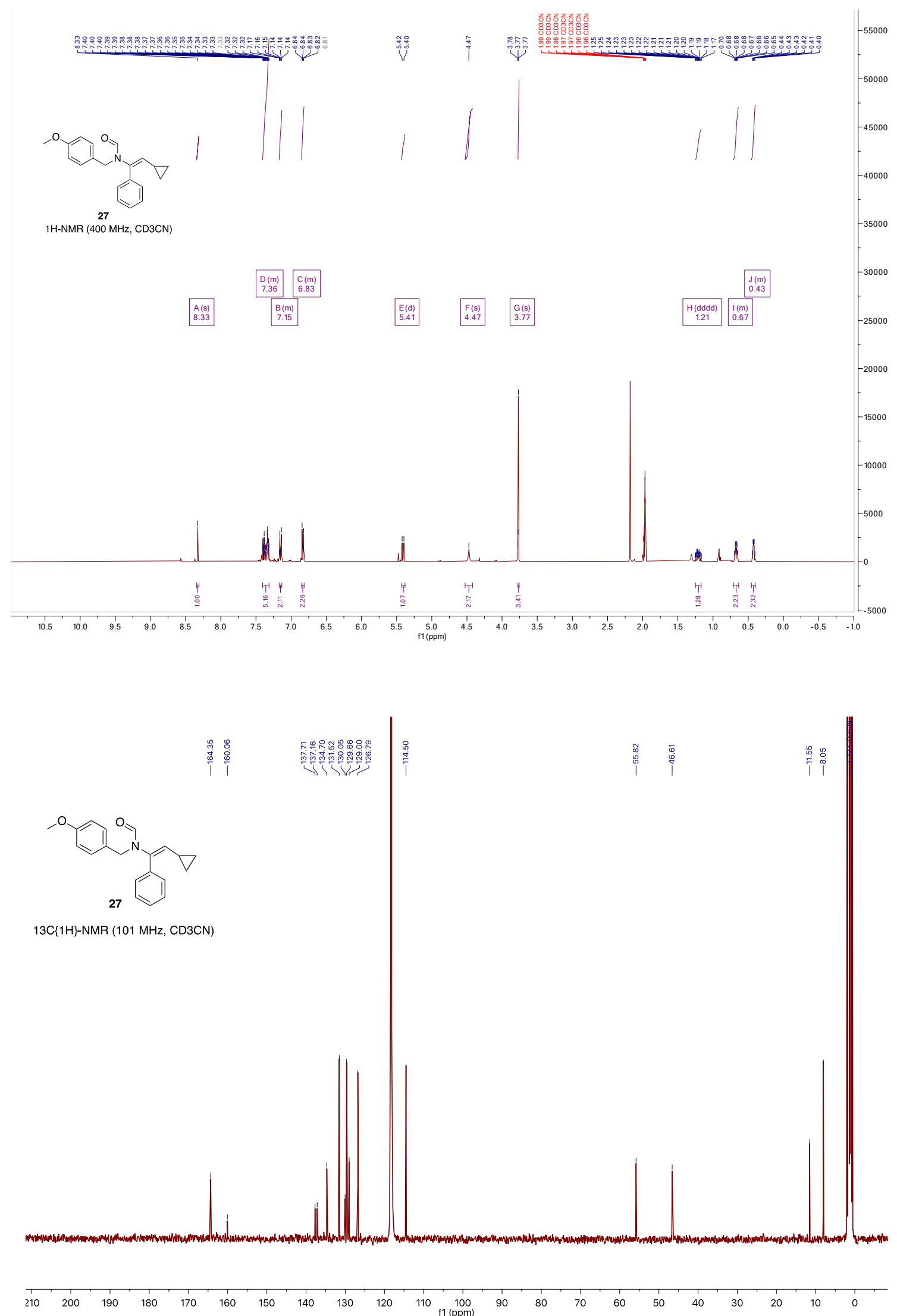